\title{
Numerical study on the response of two footings at Bothkennar research site
}

\author{
T. M. BODAS FREITAS*, D. M. POTTS $†$ and L. ZDRAVKOVIC $\dagger$
}

\begin{abstract}
This paper presents a numerical study of the performance of two instrumented surface footings at the Bothkennar Clay research site in the UK. Footing A was loaded to failure over 4 days, reaching a net bearing capacity of $q_{\mathrm{r}}=138 \mathrm{kPa}$; footing B was loaded to $89 \mathrm{kPa}$, at an identical loading rate, and left to consolidate under maintained load for about 11 years. The preloaded footing was then loaded to failure over 3 days, reaching $q_{\mathrm{r}}=204 \mathrm{kPa}$. The increase in bearing capacity was significantly larger than that expected due to consolidation effects alone, and it is anticipated that the occurrence of creep and other ageing processes may have played a major role in the observed response. The complete loading history of the two footings is simulated by means of coupled axi-symmetric finite-element analyses in which the foundation soil is described using an elastic-viscoplastic model that mimics isotach viscosity. The ground profile and the model parameters are derived based on the extensive laboratory and field test data available in the literature. The numerical analyses are able to describe accurately the footings behaviour during first loading, the development of delayed settlement under maintained load and the increase in bearing capacity due to preloading. The paper emphasises various issues regarding the application of elastic-viscoplastic models to model boundary value problems in conditions close to failure.
\end{abstract}

KEYWORDS: clays; creep; footings/foundations; numerical modelling; time dependence

\section{INTRODUCTION}

The validation of constitutive models for soils is often performed based exclusively on model simulations of typical laboratory experiments and comparison of numerical predictions with experimental results. However, a true appreciation of a model's abilities and shortcomings, and confidence in its predictions, can only be obtained if the above are supplemented with applications of the model to the analysis of boundary value problems (BVPs) for which there are performance data. In the analysis of BVPs the constitutive model is requested to predict a wide variety of stress paths, starting from different initial states, with a single set of model parameters.

In the last two decades, driven by the increasing use of numerical methods in geotechnical design, various constitutive models have been proposed to simulate the timedependent behaviour of soils, in particular clays, under general stress conditions (Liingaard et al., 2004). Owing to its simplicity and flexibility, most of these are elasticviscoplastic (EVP) models based on Perzyna's overstress theory (Perzyna, 1963; e.g. Kutter \& Sathialingam, 1992; Yin et al., 2002; Hinchberger \& Qu, 2009; Grimstad et al., 2010; Bodas Freitas et al., 2011). These models reproduce a unique stress-strain-strain rate relationship that is found to be adequate in reproducing most aspects of the timedependent behaviour of natural and reconstituted clays (Augustesen et al., 2004). However, there is still limited experience on the application of these models in the analysis of geotechnical structures (e.g. Rowe \& Hinchberger,

Manuscript received 18 May 2013; revised manuscript accepted 28 November 2014. Published online ahead of print 20 March 2015.

Discussion on this paper closes on 1 August 2015, for further details see p. ii.

* CEris, ICIST, Instituto Superior Técnico, Universidade de Lisboa, Lisbon, Portugal; formerly Imperial College London, UK.

$\uparrow$ Department of Civil and Environmental Engineering, Imperial College London, London, UK.
1998; Losacco, 2007; Karstunen \& Yin, 2010), in particular in conditions close to failure.

This paper presents the numerical analysis of the load tests carried out on two identical rigid footings at the Bothkennar research site in the UK (which was the subject of a Géotechnique symposium in print in 1992), between 1990 and 2001, as described in Jardine et al. (1995) and Lehane \& Jardine (2003). The load tests are simulated by means of coupled hydro-mechanical (consolidation) axisymmetric finite-element analyses using the Imperial College finite-element program (ICFEP) (Potts \& Zdravkovic, 1999), in which the foundation soil is modelled using an EVP model proposed by the authors (Bodas Freitas et al., 2011). This model has been shown to reproduce well time and rate effects of soils with isotach viscosity and includes some important features, namely: (a) a hyperbolic creep law to obtain realistic predictions of the long-term creep deformation of soils and geotechnical structures (Leroueil et al., 1985; Yin, 1999; Aboshi, 2004); (b) a flexible loading surface to reproduce simultaneously the soil's drained and undrained shear strength (Lagioia et al., 1996) and (c) a constant viscoplastic multiplier on any given loading surface to ensure critical state conditions are reached (Bodas Freitas et al., 2012a). The adopted ground profile and model parameters were derived based on the extensive laboratory and field testing data available in the literature (Géotechnique symposium in print in 1992 and Smith (1992)). The results obtained from these analyses can be described as type $\mathrm{C}$ predictions, that is, carried out after the event but assuming the results of the event are unknown (Lambe, 1973).

One footing (referred to as A) was loaded rapidly to failure over 4 days. The analysis of this load test will give information on the ability of the model to reproduce the various aspects of the foundation response with the adopted model parameters and to account for the difference in strain rate in the laboratory and in the field.

The other footing (B) was preloaded to two-thirds of the bearing capacity observed for footing $\mathrm{A}$ and then left for a 
period of 11 years, before being loaded to failure. The observed bearing capacity of the preloaded footing was about 1.5 times the initial value (i.e. that observed for footing A). The analysis of this test will give information on the ability of the model to predict the long-term settlement of the footing and the increase in the foundation's undrained shear strength, during the period of maintained load.

Zdravkovic et al. (2003) and Randolph et al. (2004) present a numerical study on the increase in the undrained bearing capacity of $2 \mathrm{~m}$ and $10 \mathrm{~m}$ wide strip and circular footings caused by preloading, for various ground conditions, including the case of a soft clay stratum with a surface crust, similar to the conditions found at the Bothkennar site. In these studies, the foundation soil is modelled using the time-independent modified Cam Clay (MCC) model (Roscoe \& Burland, 1968), and the gain in the foundation undrained shear strength is due to the increase in effective stresses only (i.e. consolidation). According to these results the bearing capacity of the Bothkennar preloaded footing would be about 1.25 the initial value. This is less than the observed value of 1.5 , with the difference being attributed to the inability of the MCC model to reproduce some important soil features that are likely to have contributed to the field behaviour, namely: evolving anisotropy, creep and the development of structure. The monitoring data show that most of the excess pore-water pressures generated during the application of the preload dissipated in less than a year (Jardine et al., 1995) and significant settlements were observed subsequently, denoting that creep deformations were important.

Following the work of Zdravkovic et al. (2003) and Randolph et al. (2004), Bodas Freitas et al. (2012b) analysed the short-term bearing capacity of preloaded footings, under identical conditions, considering soil hardening due to the increase in effective stresses (i.e. consolidation) and the development of creep strains, with the foundation soil being modelled using the EVP model employed herein, and the results are in close agreement with the field observations obtained at Bothkennar. In addition, previous works published in the literature (Karstunen et al., 2008; Yin \& Karstunen, 2008) suggested that when analysing the behaviour of BVPs involving sensitive soft clay deposits the effects of strain rate were dominant over those of anisotropy and destructuration. The results presented in this paper suggest that may also be the case for the Bothkennar footings.

\section{DESCRIPTION OF THE LOAD TESTS}

In June 1990, two reinforced concrete footings were constructed at the Bothkennar research site and subsequently tested, aiming to: $(a)$ investigate the bearing capacity and load-displacement behaviour of rigid footings on soft clay foundations, during short- and long-term conditions and $(b)$ support the development of relationships between the operational strength and stiffness parameters of the foundation soil and those obtained from laboratory and field testing, for different levels of applied load. The two footings, referred to as $\mathrm{A}$ and $\mathrm{B}$, were $2.2 \mathrm{~m}$ and $2.4 \mathrm{~m}$ square, respectively, with their base at $0.8 \mathrm{~m}$ depth. During casting, a $0.6 \mathrm{~m}$ square hole was left in the centre of the footings to house the instrumentation that was installed subsequently. The footings were loaded using pre-weighed blocks of kentledge placed by crane. To prevent the kentledge blocks from touching the ground, a trench approximately $0.5 \mathrm{~m}$ deep was dug around the footings.

Footing A was loaded to failure in July 1990 over a period of 4 days, reaching $q_{\mathrm{r}}=138 \mathrm{kPa}$ when the load-settlement curve approached an asymptotic value. Just before unloading, the average footing settlement was about $180 \mathrm{~mm}$. During loading the footing settled uniformly until a load factor, $L_{\mathrm{f}}$, of about 0.8 (where $L_{\mathrm{f}}=q / q_{\max }$ with $q_{\max }=138 \mathrm{kPa}$ ) and showed a maximum differential settlement of $50 \mathrm{~mm}$ just before unloading. The footing was unloaded in two stages over a period of $3 \mathrm{~h}$ and was monitored for the following 2 days.

Loading of footing B started 1 month later, in August 1990. At the start of the test, a small loading-unloading cycle was performed to investigate the ground response at small strains before loading the footing to $89 \mathrm{kPa}$ (about $67 \%$ of the bearing capcity observed for footing A). From about $L_{\mathrm{f}}=0 \cdot 35$, footing B started to tilt and, although some of the remaining weights were placed eccentrically to offset the tilt, the footing continued to rotate. Subsequent piezocone tests were unable to identify any local variation in ground conditions that could explain this tilt.

Footing B was left under maintained load for about 11 years, with no surveillance after mid-1992. During this period the footing developed significant settlements, amounting to $230 \mathrm{~mm}$ by July 2001. In 2001, following the decision to close the Bothkennar research site, the footing was loaded to failure, this being referred to as test $\mathrm{C}$. The footing was first unloaded from $89 \mathrm{kPa}$ to $60 \mathrm{kPa}$, by removing the less regularly shaped weights, and then loaded using steel kentledge only. Despite this, the tilt worsened with loading. When the applied load reached $204 \mathrm{kPa}$, the footing's maximum differential settlement and mean settlement were similar, and equal to $220 \mathrm{~mm}$ and $230 \mathrm{~mm}$, respectively, and for safety reasons the test was stopped. Based on the observations that the settlement rate reduced rapidly during the overnight break, Lehane \& Jardine (2003) inferred that the footing was still relatively stable and could possibly sustain further load.

Following the footings construction, instrumentation was installed to provide detailed information regarding the behaviour of the footings and the foundation soil during the tests. These included nine pneumatic piezometers, six spade cells (combined with pneumatic piezometer units), two inclinometers, three magnetic extensometers and 26 ground surface settlement targets, installed in the concrete footings and in the surrounding ground. In July 2001, for test C, just a small part of the instrumentation remained operational. For further details regarding the load tests the reader is referred to Gildea (1990), Jardine et al. (1995) and Lehane \& Jardine (2003).

\section{GROUND CONDITIONS}

Further to the extensive site characterisation study performed at the Bothkennar research site (see the Géotechnique symposium in print in 1992), piezocones and auger holes were made to identify the conditions relevant to the load tests. The ground conditions encountered were identical to those found elsewhere within the research site (except on the southeast corner) and are summarised in Table 1 (Jardine et al., 1995). The groundwater level was found at $0.9 \mathrm{~m}$ below ground surface (BGS). Stratum I consists of recent tidal flat deposits (the Grangemounth Beds); stratum II corresponds to a layer of shells that marks the unconformity between the Bothkennar Clay sequence (also referred to as Carse clay, that corresponds to the Claret and Letham Beds) and the recent deposits above; stratum III corresponds to the weathered facies in the top of the Bothkennar Clay sequence and stratum IV comprises the Bothkennar Clay, a soft clayey silt to silty clay that is found to extend up to about $20 \mathrm{~m}$ $\mathrm{BGS}$, and includes in the top a transition zone of lightly weathered material.

The Bothkennar clays were deposited under shallow marine and estuarine conditions, associated with the combination of the worldwide eustatic rise of sea levels 
Table 1. Ground profile at the tests location (after Jardine et al., 1995)

\begin{tabular}{|c|c|c|c|c|c|c|c|c|}
\hline Stratum & Depth: m & Soil description & $<2 \mu \mathrm{m}: \%$ & $\omega_{\mathrm{n}}: \%$ & IP: $\%$ & $I_{\mathrm{L}}: \%$ & $\gamma: \mathrm{kN} / \mathrm{m}^{3}$ & $k: \mathrm{m} / \mathrm{s}$ \\
\hline I & $0 \cdot 0-1 \cdot 0$ & Weathered clayey silt crust & 15 & 40 & 20 & $0 \cdot 4$ & $18 \cdot 0$ & $5 \cdot 0 \times 10^{-9}$ \\
\hline II & $1 \cdot 0-1 \cdot 3$ & Shells in silty clay & \multicolumn{4}{|c|}{ Not applicable } & $17 \cdot 0$ & $1.0 \times 10^{-8}$ \\
\hline III & $1 \cdot 3-2 \cdot 2$ & Soft clayey silt with some shell fragments & 15 & 50 & 30 & $0 \cdot 6$ & $17 \cdot 0$ & $5.0 \times 10^{-9}$ \\
\hline IV & $2 \cdot 2-18 \cdot 0$ & $\begin{array}{l}\text { Soft black silty clay with fine mottling } \\
\text { and occasional silt laminae }\end{array}$ & $20-40$ & $60-75$ & $30-50$ & $0 \cdot 6-1 \cdot 0$ & $16 \cdot 0$ & $2.0 \times 10^{-9}$ \\
\hline
\end{tabular}

Note: $\omega_{\mathrm{n}}=$ natural water content; IP $=$ plasticity index; $I_{\mathrm{L}}=$ liquidity index; $\gamma=$ bulk unit weight; $k=$ permeability.

superimposed on isostatic movements of the land mass due to glacial loading-unloading cycles. Post-deposition history is likely to have caused a true overconsolidation of about $15 \mathrm{kPa}$ as a result of erosion and variations in the ground water level. However, the apparent overconsolidation ratio (OCR, referred to as yield stress ratio) was found to be much higher, about 1.55 below $4 \mathrm{~m}$ depth and even larger within the surface crust (Nash et al., 1992a).

The composion of the Bothkennar Clay is fairly constant with depth, with a clay-sized fraction between $20 \%$ and $40 \%$ and a sand content well below $10 \%$. The organic content varies between $3 \%$ and $8 \%$. The plastic limit is typically about $25 \%$ and the plasticity index varies in the range $25-$ $55 \%$ depending on the specimen preparation method. The liquidity index varies in the range $1 \cdot 0-0 \cdot 6$, decreasing linearly with depth.

Bothkennar Clay was found to be prone to creep and rate effects, to be anisotropic, sensitive and slightly cemented. Therefore the engineering properties measured through laboratory and field testing where highly dependent on sample disturbance (sampling and specimen preparation methods), stress path and imposed strain rate. Based on field vane tests the sensitivity is about 5 , but laboratory fall cone tests indicated higher values, between 6 and 14. The peak undrained shear strength measured from $K_{0}$-consolidated good quality samples, sheared from in-situ stresses, is highest under triaxial compression $\left(S_{\mathrm{u}} / \sigma_{\mathrm{v} 0}^{\prime}=0 \cdot 45-0 \cdot 58\right.$, where $\sigma_{\mathrm{v} 0}^{\prime}$ is the in-situ vertical effective stress) and lowest in triaxial extension $\left(S_{\mathrm{u}} / \sigma_{\mathrm{v} 0}^{\prime}=0 \cdot 20-0 \cdot 25\right)$, with values under simple shear conditions lying in between $\left(S_{\mathrm{u}} / \sigma_{\mathrm{v} 0}^{\prime}=0 \cdot 37\right.$ $0 \cdot 47$ ). The peak effective stress strength envelope for the undisturbed clay under triaxial compression is approximately $c^{\prime}=4 \mathrm{kPa}$ and $\phi^{\prime}=37^{\circ}$ and under triaxial extension $c^{\prime}=0$ and $\phi^{\prime}=42^{\circ}$. The critical state angle of shearing resistance $\phi_{\mathrm{cs}}^{\prime}$ for reconstituted Bothkennar Clay under triaxial compression is $34^{\circ}$. Based on ring shear tests on remoulded samples the residual angle of shearing resistance was found to be $30^{\circ}$, but it is believed it could be as low as $25^{\circ}$. These strength properties are significantly higher than what would be expected based on the stress history and plasticity index alone, probably because of the high silt content and cementing (Hight et al., 1992; Smith et al., 1992).

\section{FINITE-ELEMENT ANALYSES}

\section{Problem geometry and boundary conditions}

The numerical analyses were performed using the ICFEP (Potts \& Zdravkovic, 1999). In these analyses the square footings are modelled by means of coupled axi-symmetric finite-element analyses (FEAs), considering circular footings of equivalent diameter, $D^{*}$, with the same area. Potts \& Zdravkovic (2001) show that the bearing capacity of a circular footing is only $2 \cdot 3 \%$ higher than that of a square footing with the same area, and the numerical calculations are considerably simpler and faster when using an axi- symmetric analysis instead of a full three-dimensional analysis.

Figure 1 illustrates the finite-element mesh used in the analysis of footing A, which consists of 843 eight-noded displacement-based isoparametric solid elements, with a total of 2642 nodes. Owing to symmetry considerations only half of the problem was analysed and the left-hand boundary constitutes the symmetry axis. The finite-element mesh employed in the analyses of footing B is identical to that shown in Fig. 1, except that the footing diameter has been changed from $2.48 \mathrm{~m}$ to $2.71 \mathrm{~m}$. The dimensions of the mesh and the mesh coarseness were defined such that they would not influence the analyses results. The analyses were performed using small displacement theory. The analyses simulate the full loading history, including the excavation for the footing, the casting, the waiting time until the start of the loading test and the specific loading sequence of each load test.

Figure 1 also shows the displacement and pore-water pressure boundary conditions specified along the mesh boundaries. The bottom of the mesh was prevented from moving in the horizontal and vertical directions, the lateral boundaries were prevented from moving in the horizontal direction only, and the ground surface was a stress-free boundary. The footings were not simulated using solid elements; instead their weight and subsequent loading were

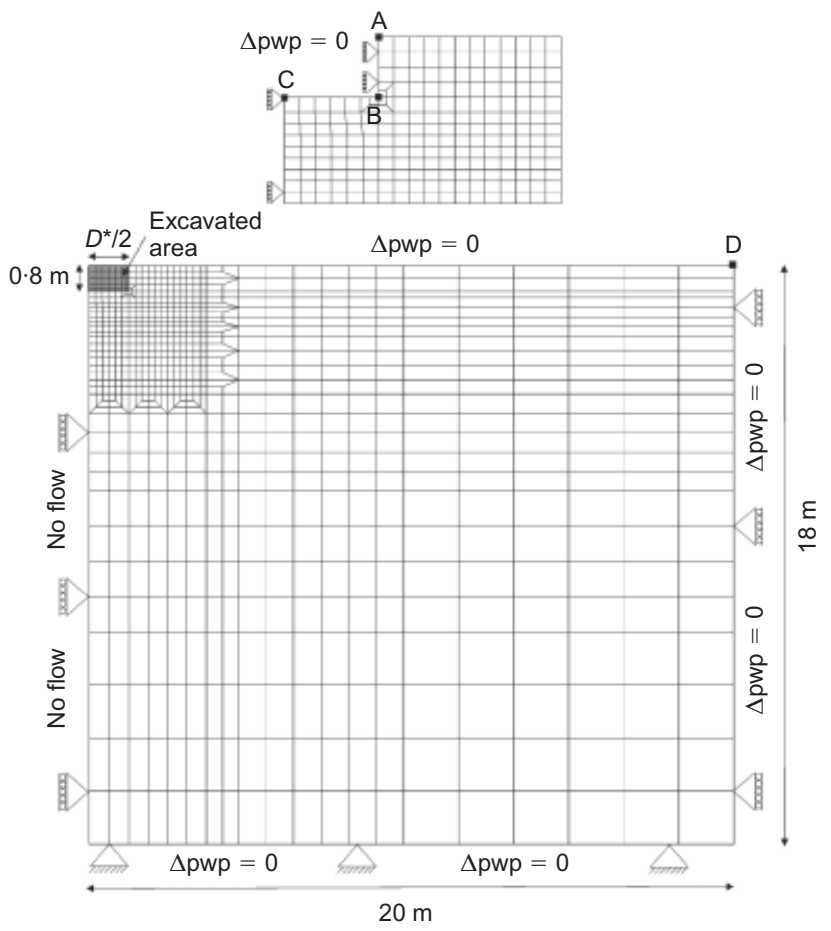

Fig. 1. Finite-element mesh and boundary conditions ('pwp' denotes pore-water pressure) 
simulated by applying an equivalent uniform stress along the boundary BC.

To mimic the behaviour of a rough rigid footing, along the boundary $\mathrm{BC}$ the horizontal displacements were set equal to zero and the vertical displacements were made to have the same magnitude. This latter condition was achieved by using the tied degrees of freedom concept in which the movements in a particular direction, along a certain boundary, can be set to have the same magnitude; however, this magnitude is not specified but is a result of the analysis (see Potts \& Zdravkovic, 1999). Following the construction of the footings, the horizontal displacements are set equal to zero along the boundary $\mathrm{AB}$.

The specified pore-water pressure boundary conditions are: $(a)$ no flow of water along the axis of symmetry; $(b)$ no change in pore-water pressure along the bottom and righthand boundaries; $(c)$ no change in pore-water pressure along the ground surface (boundary AD) as the soil is assumed to be able to sustain negative pore-water pressure (suctions) and $(d)$ no pore-water pressure change at the contact between the concrete and the ground (boundaries $\mathrm{AB}$ and $\mathrm{BC}$ ); that is, it is a drained boundary in agreement with the field measurements.

\section{Constitutive model}

The constitutive model used to simulate the foundation soil is an overstress-based EVP model that is able to reproduce permanent strain rate effects in the soil response (i.e. isotach viscosity, see Augustesen et al. (2004)). The model is described in detail in Bodas Freitas et al. (2011). The underlying assumption of this type of model is that the soil deformation, associated with the application of an effective stress increment, $\left\{\Delta \sigma^{\prime}\right\}$, over a time increment, $\Delta t$, is decomposed into an elastic and a viscoplastic part

$$
\left\{\Delta \varepsilon^{\mathrm{T}}\right\}=\left\{\Delta \varepsilon^{\mathrm{el}}\right\}+\left\{\Delta \varepsilon^{\mathrm{vp}}\right\}
$$

where $\left\{\Delta \varepsilon^{\mathrm{el}}\right\}$ is the elastic strain increment and $\left\{\Delta \varepsilon^{\mathrm{vp}}\right\}$ is the viscoplastic strain increment. The elastic strain increment, $\left\{\Delta \varepsilon^{\mathrm{el}}\right\}$, can be determined by inverting equation (2).

$$
\left\{\Delta \sigma^{\prime}\right\}=\left[D^{\prime}\right] \cdot\left\{\Delta \varepsilon^{\mathrm{el}}\right\}
$$

where $\left[D^{\prime}\right]$ is the elastic constitutive matrix. The elastic response is assumed to be isotropic and is fully characterised by two elastic parameters, a stress-dependent bulk modulus $K$ (defined by equation (3), in which $V$ is the specific volume, $\kappa / V$ is a material parameter and $p^{\prime}$ is mean effective stress) and a second elastic parameter that can be either the Poisson ratio, $v$, or the elastic shear modulus, $G$.

$$
K=\frac{V p^{\prime}}{\kappa}
$$

Based on the overstress theory proposed by Perzyna (1963), the viscoplastic strain increment is evaluated as

$$
\left\{\Delta \varepsilon^{\mathrm{vp}}\right\}=\langle\Phi\rangle\left\{\frac{\partial g}{\partial \sigma^{\prime}}\right\} \Delta t
$$

where $\langle\Phi\rangle=\Phi$ if the stress state lies outside the yield surface, $\langle\Phi\rangle=0$ if the stress state lies on or inside the yield surface, $\Phi$ is the viscoplastic scalar multiplier and $g$ is the plastic potential, which is, in principle, different from the current loading surface. The value of $\Phi:(a)$ is determined using the concept of equivalent time (Yin \& Graham, 1989; Yin et al., 2002; Bodas Freitas et al., 2011); (b) incorporates a hyperbolic law to describe the variation of volumetric viscoplastic (creep) strains with time under an isotropic effective stress state (Yin, 1999); and (c) assumes that $\Phi$ is constant for all stress states located on a given loading surface (Bodas Freitas et al., 2012a). Based on the latter assumption, the problem of determining $\Phi$ at a general state $\left(p^{\prime}, J, \varepsilon_{\mathrm{vol}}\right)$, where $J$ is an invariant deviatoric stress and $\varepsilon_{\mathrm{vol}}$ is volumetric strain, is reduced to calculating $\Phi$ at the equivalent isotropic state $\left(p^{\prime}=p_{\mathrm{m}}^{\prime}, J=0, \varepsilon_{\mathrm{vol}, \mathrm{m}}\right)$, where $p_{\mathrm{m}}^{\prime}$ is the mean effective stress at $J=0$ on the current loading surface, and the geometric significance of the quantity $\varepsilon_{\mathrm{vol}, \mathrm{m}}$ is illustrated in Fig. 2. $\Phi$ is computed using equation (5).

$$
\begin{aligned}
\Phi= & \frac{\psi_{0}}{V t_{0}}\left(1+\frac{\varepsilon_{\mathrm{vol}, \mathrm{m}}^{\mathrm{ref}}-\varepsilon_{\mathrm{vol}, \mathrm{m}}}{\varepsilon_{\mathrm{vol}, \mathrm{m}, \mathrm{Limit}}^{\mathrm{vp}}}\right)^{2} \\
& \exp \left[\frac{V}{\psi_{0}} \frac{\varepsilon_{\mathrm{vol}, \mathrm{m}}^{\mathrm{ref}}-\varepsilon_{\mathrm{vol}, \mathrm{m}}}{\left.\left(1+\frac{\varepsilon_{\mathrm{vol}, \mathrm{m}}^{\mathrm{ref}}-\varepsilon_{\mathrm{vol}, \mathrm{m}}}{\varepsilon_{\mathrm{vol}, \mathrm{m}, \mathrm{Limit}}^{\mathrm{vp}}}\right)\right]}\right] \frac{1}{\left|\frac{\partial g}{\partial p^{\prime}}\right|_{\substack{p^{\prime}=p_{\mathrm{m}}^{\prime} \\
J=0}}}
\end{aligned}
$$

where: $t_{0}, \psi_{0} / V$ and $\varepsilon_{\mathrm{vol}, \mathrm{m}, \mathrm{Limit}}^{\mathrm{vp}}$ are input model parameters; $\varepsilon_{\mathrm{vol,m}}$ is the current volumetric strain at $p=p_{\mathrm{m}}^{\prime} ; \varepsilon_{\mathrm{vol,m}}^{\mathrm{ref}}$ is the volumetric strain on the reference line at $p^{\prime}=p_{\mathrm{m}}^{\prime}$; and $\left|\partial g / \partial p^{\prime}\right|_{p^{\prime}=p_{\mathrm{m}}^{\prime}}$ is the partial derivative of the plastic potential function, ${ }^{J}=0$, in relation to the mean effective stress, $p^{\prime}$, evaluated at the equivalent isotropic stress state $\left(p^{\prime}=p_{\mathrm{m}}^{\prime}, J=0\right)$, the absolute value function being introduced to ensure that $\Phi$ is always a positive quantity.

The loading and the plastic potential surfaces are described by a flexible function that can reproduce a wide range of shapes, requiring three model parameters $\alpha, \mu$ and $M$ (Lagioia et al., 1996). $M$ is the inclination of the critical state line in $p^{\prime}-q$ space (where $q$ is the triaxial deviatoric stress) under triaxial compression, and $\alpha$ and $\mu$ control the
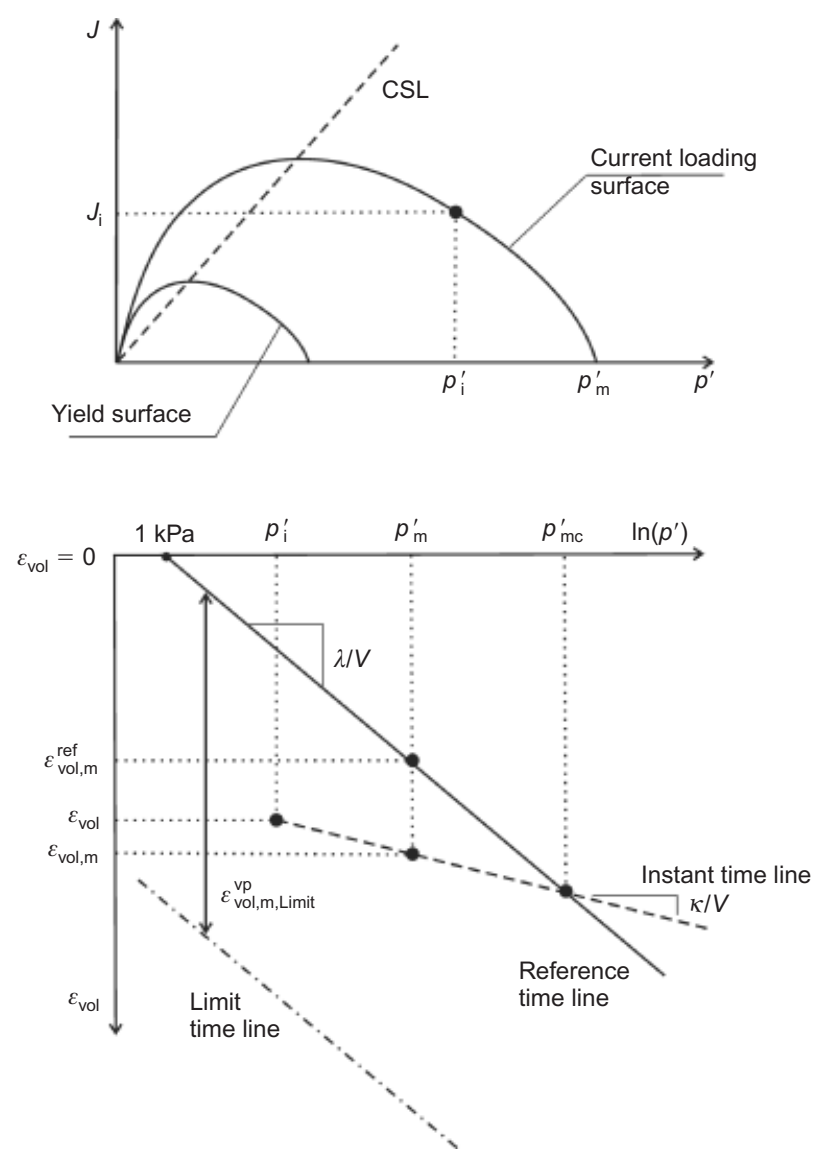

Fig. 2. Constitutive model framework 
shape of the surfaces. The values of $\alpha$ and $\mu$ are determined by curve fitting the effective stress paths of undrained triaxial tests, aiming to reproduce the soil's undrained shear strength, $S_{\mathrm{u}}$, under the predominant loading condition (in this case triaxial compression). In the deviatoric plane loading and plastic potential surfaces are described by the equation of the Matsuoka-Nakai failure criterion. Table 2 shows all the required model parameters and their meaning.

At the start of the analysis procedure the initial volumetric strain, $\varepsilon_{\mathrm{vol}}$, is initialised as

$$
\varepsilon_{\mathrm{vol}}=\frac{\lambda}{V} \ln \left(p_{\mathrm{mc}}^{\prime}\right)-\frac{\kappa}{V} \ln \left(\frac{p_{\mathrm{mc}}^{\prime}}{p_{\mathrm{i}}^{\prime}}\right)
$$

where $p_{\mathrm{i}}^{\prime}$ is the initial mean effective stress and $p_{\mathrm{mc}}^{\prime}$ the size of the loading surface corresponding to the largest normally consolidated stress state that the soil element has experienced.

During the analysis procedures $\varepsilon_{\mathrm{vol}}$ is updated as follows

$$
\Delta \varepsilon_{\mathrm{vol}}=\Delta \varepsilon_{x}+\Delta \varepsilon_{y}+\Delta \varepsilon_{z}
$$

In addition, $\varepsilon_{\mathrm{vol}, \mathrm{m}}$ and $\varepsilon_{\mathrm{vol}, \mathrm{m}}^{\mathrm{ref}}$ are calculated as

$$
\begin{aligned}
& \varepsilon_{\mathrm{vol}, \mathrm{m}}=\varepsilon_{\mathrm{vol}}+\frac{\kappa}{V} \ln \left(\frac{p_{\mathrm{m}}^{\prime}}{p^{\prime}}\right) \\
& \varepsilon_{\mathrm{vol}, \mathrm{m}}^{\mathrm{ref}}=\frac{\lambda}{V} \ln \left(p_{\mathrm{m}}^{\prime}\right)
\end{aligned}
$$

The size of the yield surface is controlled by the parameter $\varepsilon_{\mathrm{vol}, \mathrm{m}, \text { Limit }}^{\mathrm{vp}}$ that is assumed to be constant (see Fig. 2). Assuming contractive volumetric strains are positive, the onset of viscoplastic deformation can be expressed as

$$
1+\frac{\varepsilon_{\mathrm{vol,m}}^{\mathrm{ref}}-\varepsilon_{\mathrm{vol}, \mathrm{m}}}{\varepsilon_{\mathrm{vol,m}, \text { Limit }}^{\mathrm{vp}}}>0
$$

\section{Model parameters}

The model parameters were derived based on the extensive laboratory test data reported in the literature (see the Géotechnique symposium in print in 1992), in particular Smith et al. (1992), Smith (1992) and Nash et al. (1992b), mainly on samples from 5.3 to $6.2 \mathrm{~m}$ depth. The derivation of the model parameters for unweathered Botheknenar Clay is presented in detail in Bodas Freitas et al. (2011), and they are summarised in Table 2. The parameter $\lambda / V$ was taken as the average inclination of the normal compression curve in $\varepsilon_{\mathrm{vol}}-\ln p^{\prime}$ space over the applied stress range.

Figure 3 shows the effective stress paths obtained from five undrained triaxial compression and extension tests on intact samples of Bothkennar Clay from $5.3 \mathrm{~m}$ and $6.2 \mathrm{~m}$ depth, and the model predictions obtained by means of FEA that simulate the complete loading sequence and use the parameters given in Table 2. The predictions reproduce reasonably well the peak undrained shear strength under triaxial compression and its variation with applied axial
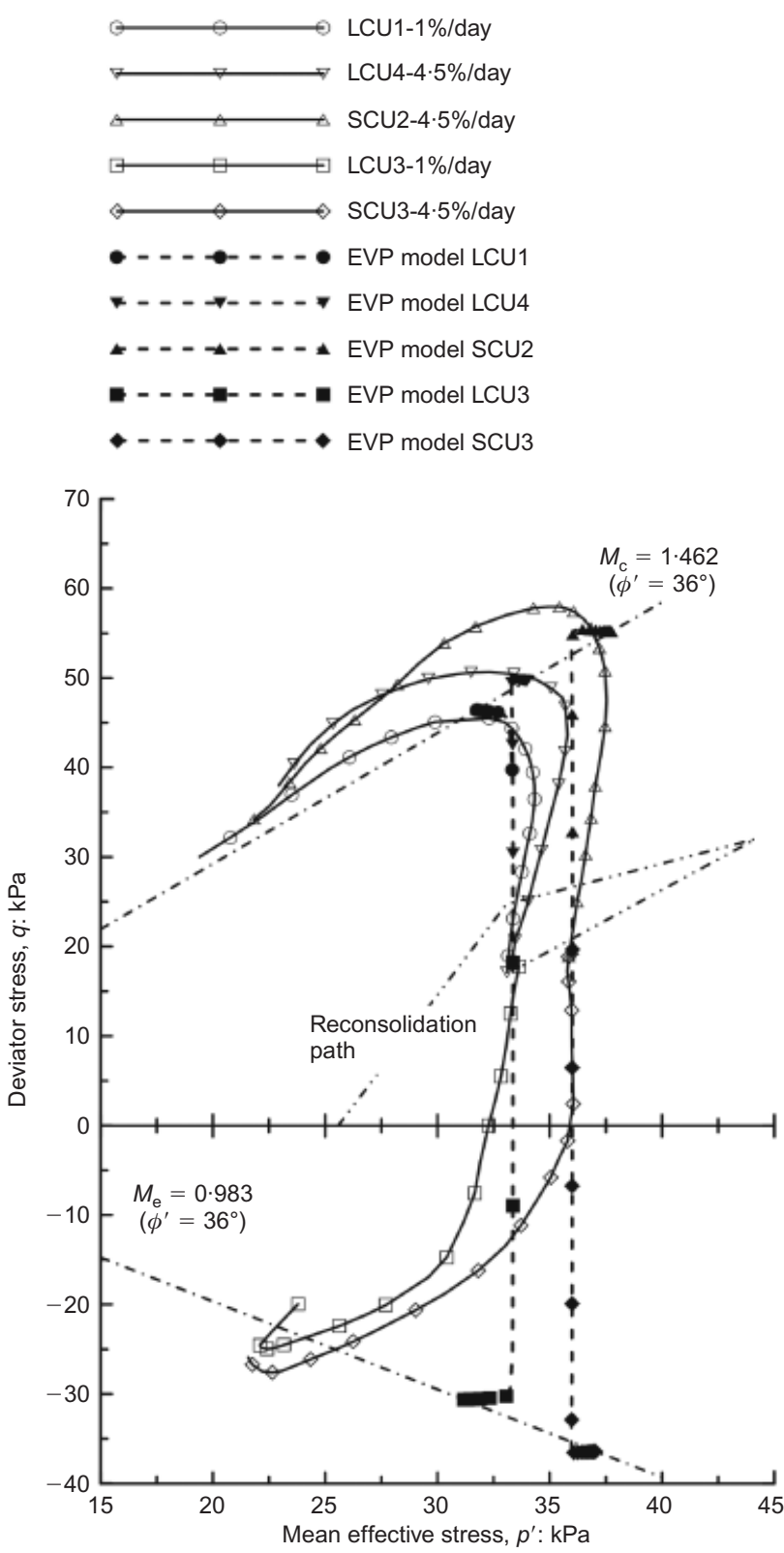

Fig. 3. Laboratory data and numerical predictions of $K_{0}-$ consolidated undrained triaxial compression and extension tests on natural samples of Bothkennar Clay

strain rate; however, they are unable to reproduce the full stress-strain response, in particular the post-peak strength loss due to destructuration. Because the parameters $\alpha$ and $\mu$ were derived to match $S_{\mathrm{u}}$ under triaxial compression, significant divergence is observed under triaxial extension.

The model parameters included in Table 2 correspond to unit IV (see Table 1). Given the limited amount of test data

Table 2. Adopted model parameters

\begin{tabular}{l|c|c|c|c|c|c|c|c|c|c}
\hline$M$ & $\alpha$ & $\mu$ & $\lambda / V$ & $\kappa / V$ & $v$ & $t_{0}$ & $\psi_{0} / V$ \\
- & - & - & - & - & - & $\begin{array}{c}\varepsilon_{\mathrm{vol}, \mathrm{m}, \mathrm{Limit}} \\
-\end{array}$ \\
\hline 1.462 & 0.05 & 0.85 & 0.0842 & 0.0105 & 0.26 & 1.0 & 0.00378 & 0.065 \\
\hline
\end{tabular}

Note: $M$ is the $q / p^{\prime}$ value at critical state, under triaxial compression; $\alpha$ and $\mu$ are parameters that control the shape of the loading and plastic potential surfaces; $\lambda / V$ is the slope of the reference time line (i.e. the normal compression line) in $\varepsilon_{\mathrm{vol}}-\ln p^{\prime}$ space; $\kappa / V$ is the slope of the elastic line (i.e. unloading/reloading line) in $\varepsilon_{\mathrm{vol}}-\ln p^{\prime}$ space; $v$ is Poisson ratio; $t_{0}$ is real time associated with the reference compression line; $\psi_{0} / V$ is the slope of the $\varepsilon_{\mathrm{vol}}-\ln t$ curve at $t=t_{0}=1$ day; $\varepsilon_{\mathrm{vol}, \mathrm{m}, \text { Limit }}$ is the limit to the amount of volumetric viscoplastic strain; $e_{0}$ is initial void ratio; and OCR is the overconsolidation ratio - this value applies below $4 \mathrm{~m}$ depth; in the top $4 \mathrm{~m}$ the value of OCR varies with depth as shown in Fig. 3 . 
available within units I to III, and noting that these units have a limited extent below the base of footings, the same model parameters have been attributed to units I to III, and the differences in strength and stiffness are assumed to result from differences in the soil initial state (i.e. defined by the coefficient of earth pressures at rest, $K_{0}$, and the OCR). Fig. 4 shows the profiles of $K_{0}$ and OCR adopted in the analyses compared with the available laboratory and in-situ test data.

The permeability was defined from in-situ and laboratory test data at the in-situ void ratio (Leroueil et al., 1992; Nash et al., 1992b). The ratio of horizontal to vertical permeability lies between $1 \cdot 1$ and 1.6 in the top $12 \mathrm{~m}$ of the soft clay layer. This permeability anisotropy was regarded to be small and, consequently, an isotropic permeability was considered in the analyses. There were no permeability data for the superficial materials and so values typical for these materials were adopted (see Table 1).

The initial effective stresses were calculated using: $(a)$ the bulk unit weight values included in Table 1; $(b)$ a hydrostatic pore-water pressure profile with the groundwater level at $0.9 \mathrm{~m}$ depth and $(c)$ the $K_{0}$ profile shown in Fig. 4 .

Figure 5 shows the profile of peak undrained shear

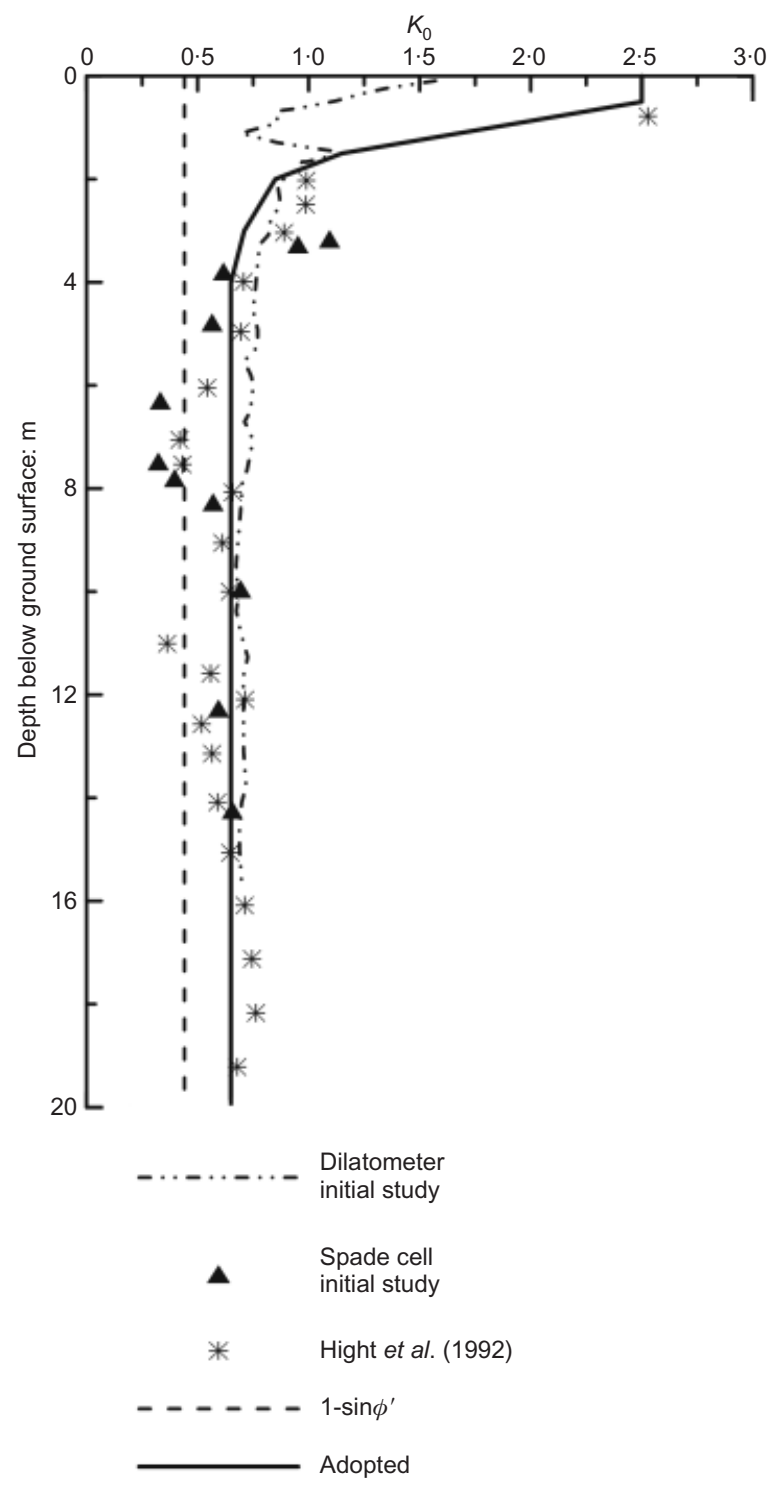

strength, $S_{\mathrm{u}}$, with depth, under triaxial compression, predicted by the EVP model at an axial strain rate equal to $4.5 \%$ /day and laboratory test results obtained under identical loading conditions. Each data point of the predicted $S_{\mathrm{u}}$ profile was obtained by means of a single element FEA that simulated a consolidated undrained triaxial compression test at $4.5 \%$ /day axial strain, with the adopted initial effective stresses and OCR for each depth. The $S_{\mathrm{u}}$ profile predicted by the EVP model fits well the laboratory data in the top $8 \mathrm{~m}$; below this depth, there is significant divergence, but the strength values are unlikely to impact on the footing response. Following the parameter derivation, no further adjustments were made to the parameters to improve the numerical predictions.

\section{ANALYSES RESULTS}

In the following sections the results obtained from the numerical analyses are presented and compared with the field data. The data regarding the loading and short-term response of footings $\mathrm{A}$ and $\mathrm{B}$ were taken from Jardine et al. (1995). The data of the long-term response of footing B

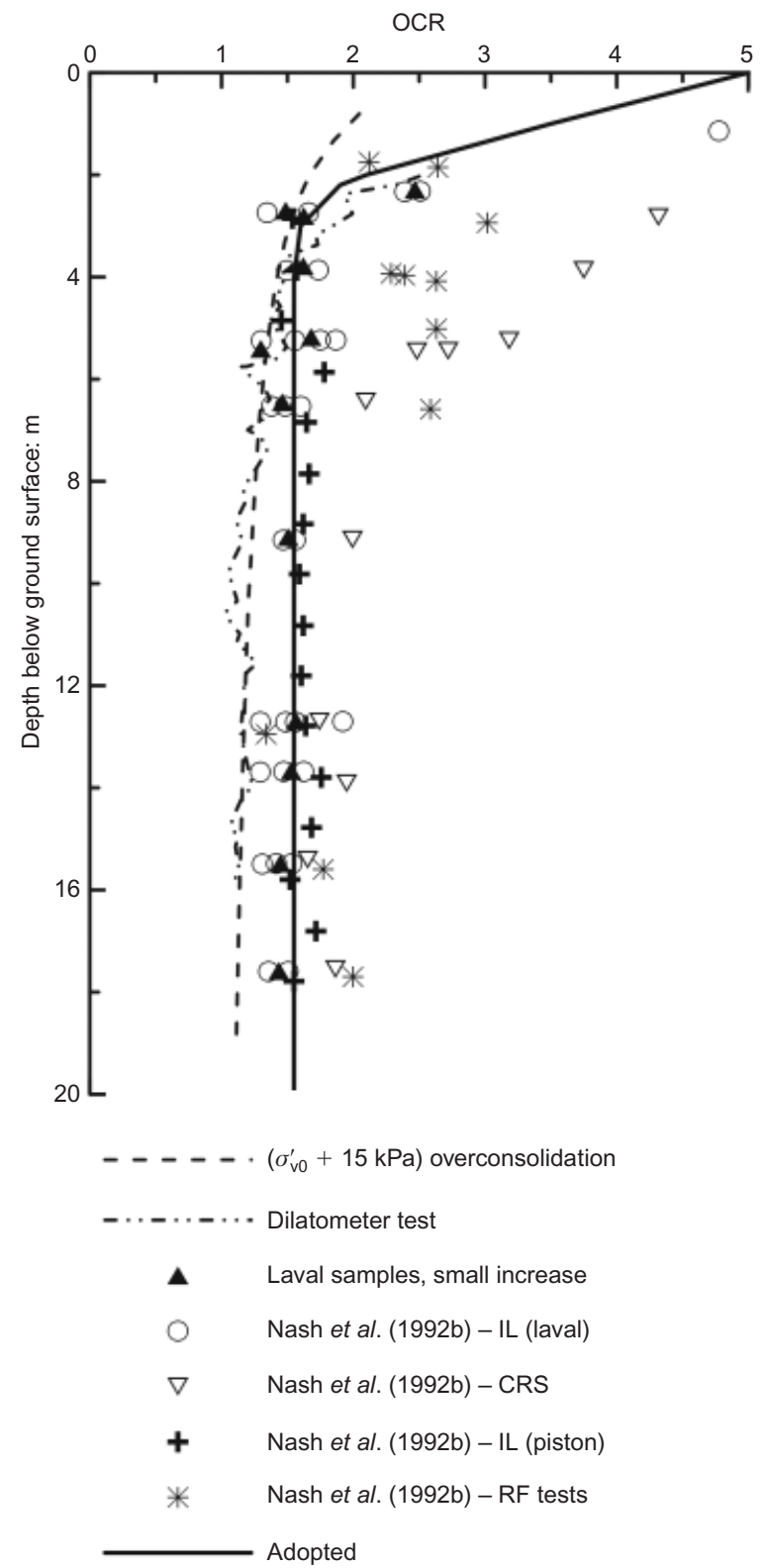

Fig. 4. $K_{0}$ and OCR profiles 


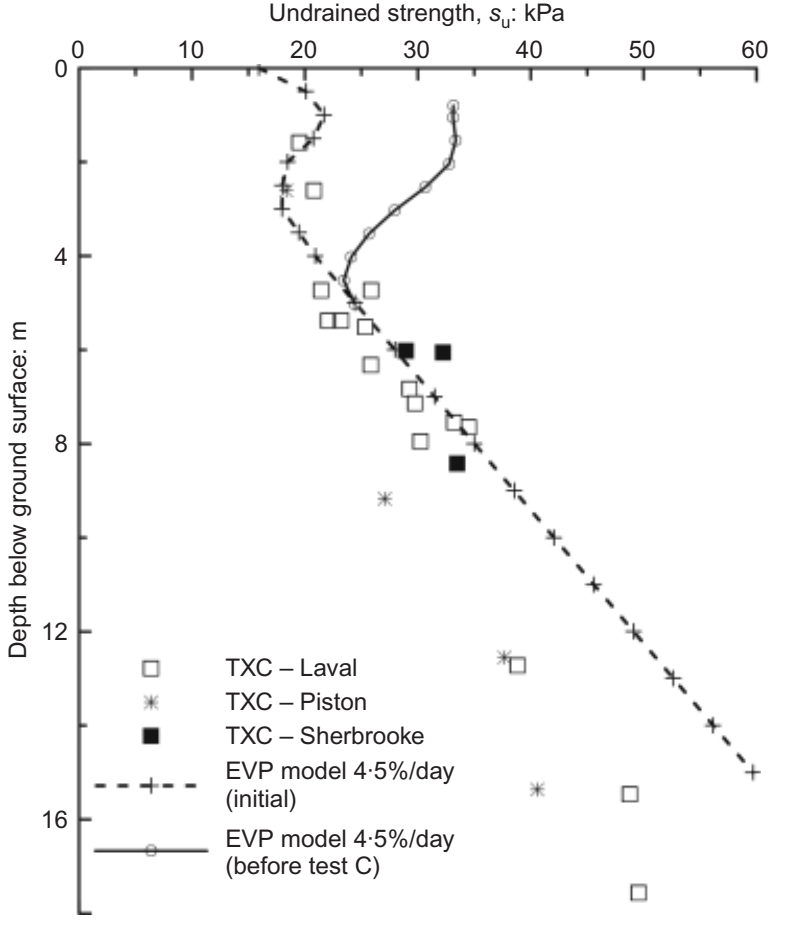

Fig. 5. Peak undrained shear strength profile

under preload and the subsequent load test $\mathrm{C}$ were taken from Lehane \& Jardine (2003).

\section{General load-displacement behaviour}

Figure 6 shows the recorded variation of applied load and footing settlement with time during the load tests, and compares the field data with the numerical predictions. For tests $\mathrm{A}$ and $\mathrm{C}$, measurements from the individual targets located on the mid-sides of the footing are available; for test B only the average footing settlement is reported in the literature. Fig. 7 shows the field and predicted load-displacement curves. Based on Figs 6 and 7 the following comments can be made.

(a) In tests $\mathrm{A}$ and $\mathrm{B}$, the numerical analyses overpredict the footing settlement during the early loading stages, up to $75 \mathrm{kPa}$, and underpredict it at intermediate and high applied stresses, up to failure. However, in general terms, the numerical predictions approximate well the field data, in particular when considering the average footing settlement. Differences between the observed and predicted data may be associated with soil features not reproduced by the adopted soil model, such as initial anisotropy and its evolution during loading and soil destructuration.

(b) Following the application of the last load increment the average settlement of footing A was about $140 \mathrm{~mm}$, increasing to $180 \mathrm{~mm}$ just before the footing unloading. These values compare well with $123 \mathrm{~mm}$ and $172 \mathrm{~mm}$ obtained in the numerical analyses, in the same instances. Furthermore, very little settlement was recovered following the footing unloading, an aspect well reproduced by the numerical analysis.

(c) Despite the severe tilting of footing $\mathrm{B}$, the measured load-settlement behaviour of test B is similar to that of test A, suggesting that footings $\mathrm{A}$ and $\mathrm{B}$ had identical initial bearing capacity.

(d) Eleven years of preloading caused a significant increase of the foundation strength and stiffness; test $\mathrm{C}$ reached a bearing capacity of $204 \mathrm{kPa}$ ( $48 \%$ higher than test A) and up to $160 \mathrm{kPa}$ the footing response is very stiff (identical
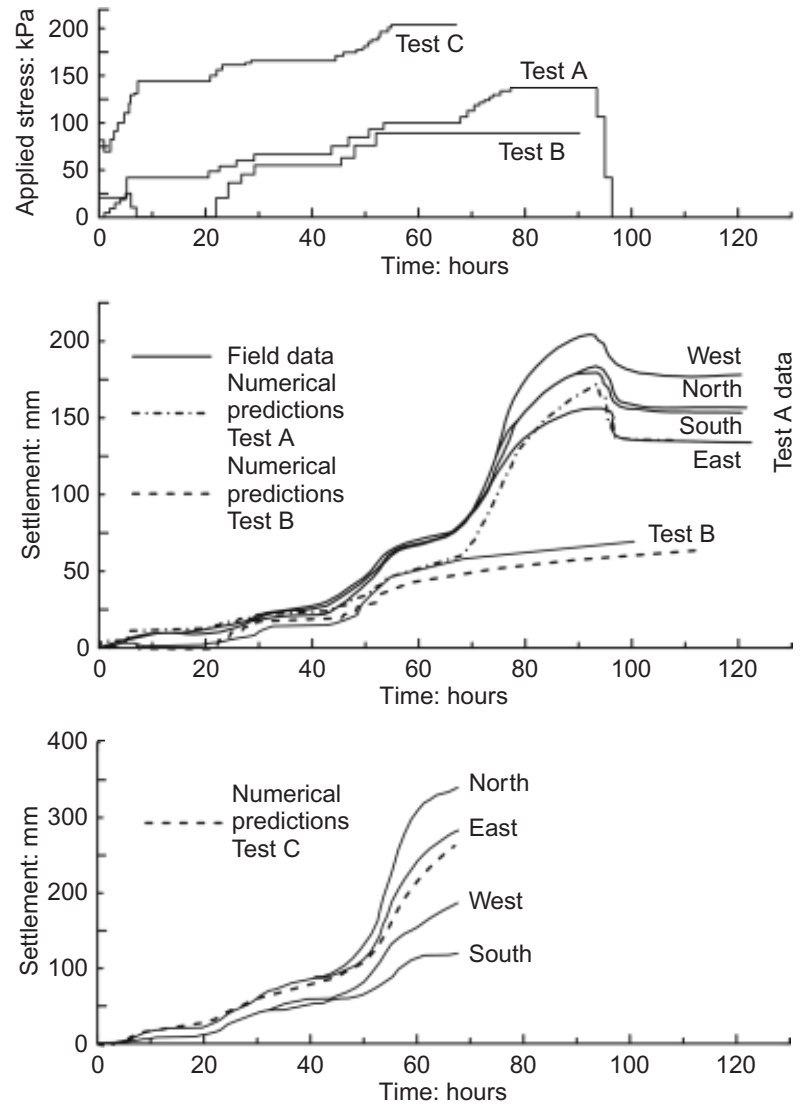

Fig. 6. Time-load and time-displacement histories

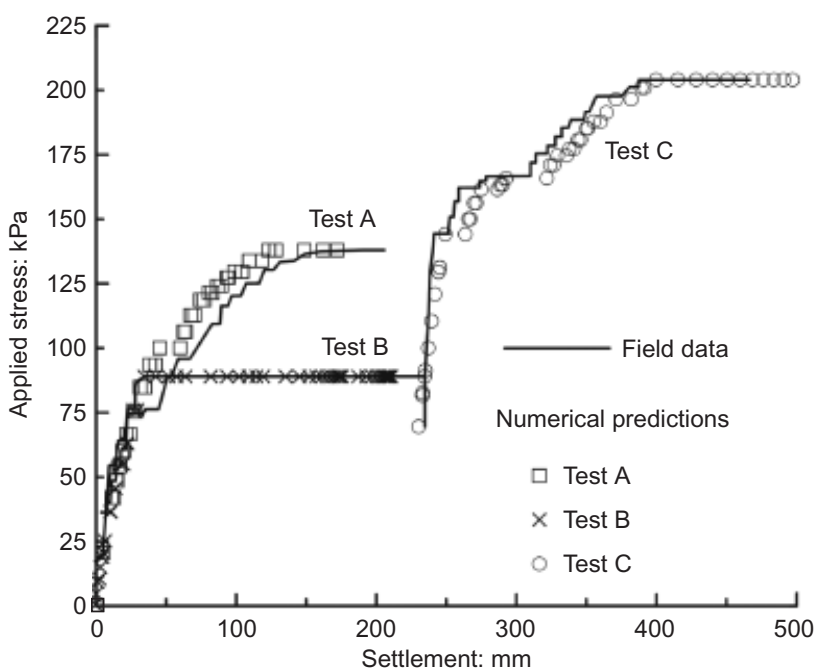

Fig. 7. Load-displacement curves (field data for test A corresponds to maximum settlement; field data for tests $B$ and $C$ corresponds to mean settlement)

to that observed during the initial loading stages of tests $\mathrm{A}$ and $\mathrm{B}$, up to $80 \mathrm{kPa}$ ), both aspects being well reproduced by the numerical analyses.

(e) In test $\mathrm{C}$, after the application of the last load increment, the average footing settlement was about $155 \mathrm{~mm}$, increasing to 230 at the end of the overnight break. These values compare well with $165 \mathrm{~mm}$ and $263 \mathrm{~mm}$ obtained in the numerical analysis.

Footing settlement under maintained load

Figure 8 shows the variation of footing settlement with time, since the start of test B until the end of the period of 


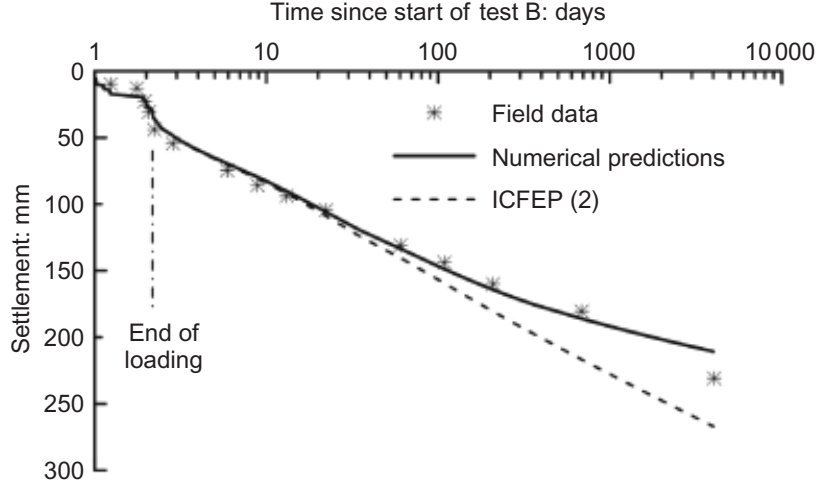

Fig. 8. Footing settlement under maintained load

maintained load, and compares the field data with the finiteelement predictions. From these data it is not possible to identify a period of primary consolidation, as seen elsewhere (e.g. Bjerrum, 1967). From about 60 days onwards, the field data show a slight tendency for the settlement rate to decrease, which is well recovered by the FEA. The last two readings are over 9 years apart; therefore the last field reading, which deviates considerably from the previous trend, should be treated with caution. With the exception of this last data point, the finite-element predictions provide a remarkable match to the field data.

To illustrate the effect of considering the soil creep nonlinearity on the prediction of the footing settlement during maintained load, an additional analysis was performed (ICFEP 2) that differs from the previous one merely in the value adopted for the parameter $\varepsilon_{\text {vol,m,Limit }}^{\mathrm{vp}}$ (this was set equal to the volumetric strain required to cause the soil to have no voids, i.e. $e_{0} /\left(e_{0}+1\right)$, such that the model predicts a creep response close to that of a semi-logarithmic creep law for the time interval considered).

\section{Foundation response}

This section examines the ability of the FEA to recover the response of the foundation soil during and after the load tests, in terms of induced movements and stress changes. The response of the foundation soil was characterised through a series of devices, which were monitored until mid-1992 and then again during test $\mathrm{C}$ in 2001. Most of the monitoring devices were damaged during the period of maintained load and during test $\mathrm{C}$ only a small number of them were functional, making the interpretation of measurements more challenging (Lehane \& Jardine, 2003).

Centreline settlements. Extensometers were installed under footings A and B. Fig. 9 shows the profile of settlements with depth at the footing axis during tests $\mathrm{A}$ and $\mathrm{B}$, for different values of applied load, and compares the field data with the numerical predictions. The field data confirm that, despite the accentuated tilting of footing $\mathrm{B}$, the behaviour of tests $\mathrm{A}$ and $\mathrm{B}$ is comparable.

The FEAs are found to predict reasonably well the settlement at the base of the footing, but fail to recover the profile of settlements with depth. The field data indicate that the settlement reduces sharply with depth, being negligible below 1.5 to $2.0 \mathrm{~m}$ below the footing base; the FEAs predict a deeper settlement profile, which extends up to $3 \cdot 0$ to $3.5 \mathrm{~m}$. These differences may result from not considering, in the numerical analysis, the soil anisotropy and its evolution during loading, the occurrence of destructuration, the fact that the same model parameters (with exception of OCR and

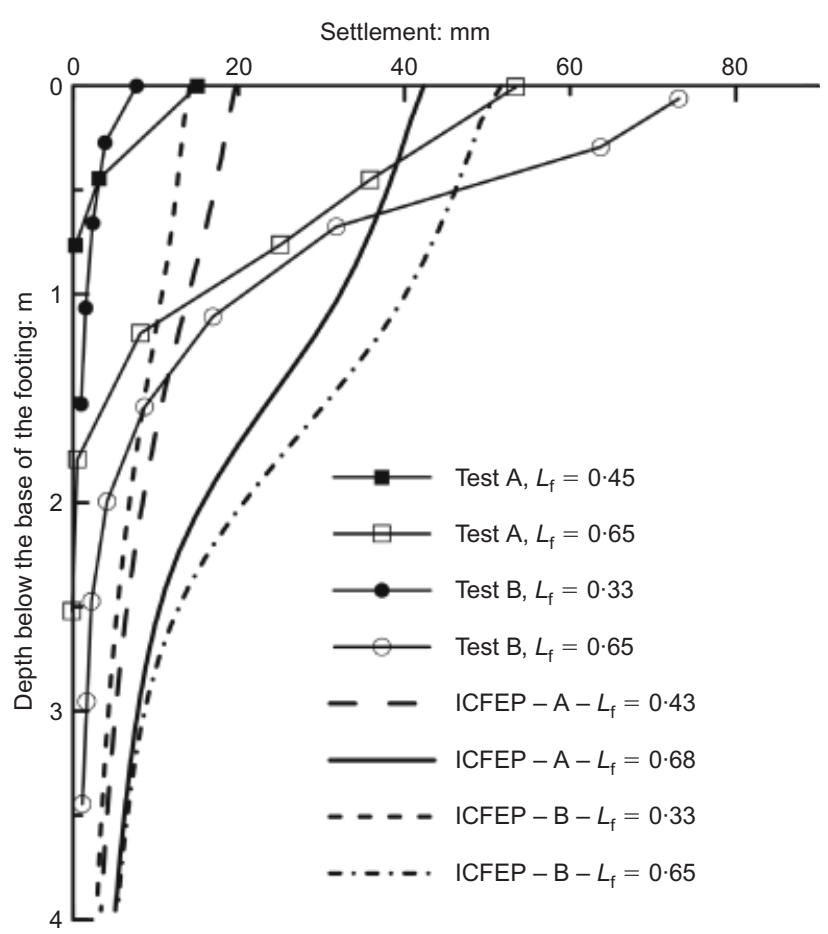

Fig. 9. Settlement profile with depth - tests A and B

$K_{0}$ ) were adopted over the full depth of the soil profile, and, to a lesser extent, the fact that the elastic component of the EVP model is based on a stress-dependent bulk and shear stiffnessess and cannot account for the soil's strong nonlinearity (and very stiff response) at small strains.

At the time of test $\mathrm{C}$, the extensometer under footing B was still operational. The data obtained during test $\mathrm{C}$ (Lehane \& Jardine, 2003) indicate that, close to failure, significant settlements may have occurred up to $4.5 \mathrm{~m}$ below the base of the footing (i.e. suggesting a deeper mechanism to that observed in test $\mathrm{A}$ ), but the data have evident errors for $q_{\mathrm{r}}$ above $185 \mathrm{kPa}$ (namely tension between 1.5 and $3 \mathrm{~m}$ below the base of the footing) and thus these data are not considered here.

Pore-water pressures. A large number of piezometers were installed in the foundation soil, under footings A and B. Given the similarities between tests A and B, only the results from test $\mathrm{B}$ are presented here. Fig. 10 shows the variation of pore-water pressure in the piezometers located at the axis of footing B, from the end of the test (August 1990) until mid1992, and compares the field data with the FEA results.

The amount of excess pore-water pressure generated, at a certain depth, at the end of loading depends fundamentally on the magnitude of the imposed total stress increment and the drainage conditions. At shallow depth, the stress changes imposed by loading, and thus the potential excess pore-water pressure, are larger; however, the proximity to the drainage boundary (and the field data suggest the base of the footing acted as a drainage boundary, e.g. PZ4B has minimal excess pore-water pressure), causes the consolidation to occur faster than at depth. This is supported by the field data, showing the dissipation time increasing with depth, that is, with the distance to the drainage boundary.

Overall, the FEA overpredicts the amount of excess porewater pressure at the end of loading in the piezometers located in the top $2.5 \mathrm{~m}$ (PZ2B, PZ3B, PZ4B, the difference being larger at shallower depth) and slightly underpredicts below that (PZ5B). At $6.6 \mathrm{~m}$ depth (PZ6), both the field data 

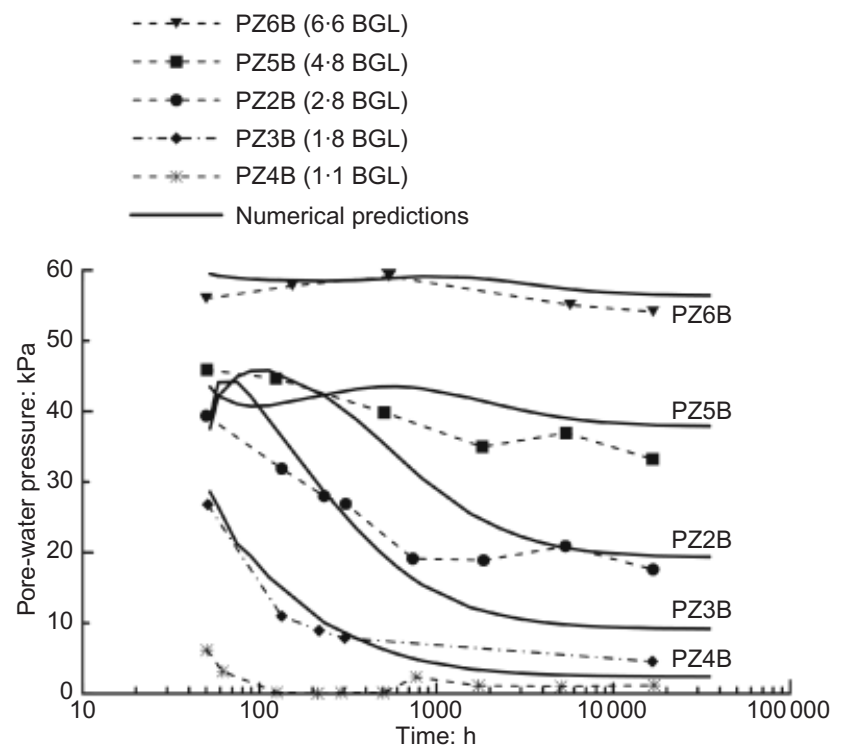

Fig. 10. Variation of excess pore-water pressure with time for footing $B$ (piezometer depth is approximate, extrapolated from Jardine et al. (1995))

and the numerical predictions indicate minimal excess porewater pressure, suggesting that at this depth the changes in total stress are practically insignificant (Jardine et al., 1986). This can be better appreciated in Fig. 11, which shows the profile of excess pore-water pressure with depth (normalised

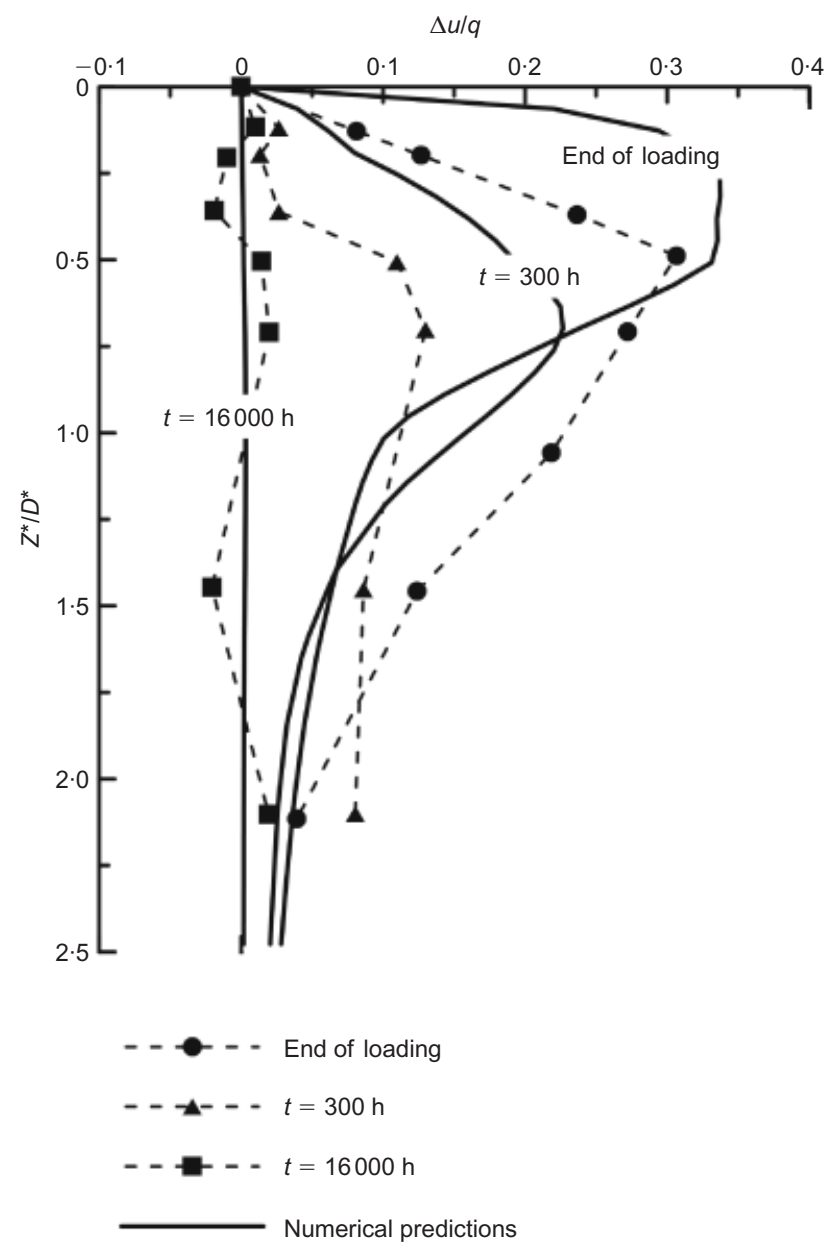

Fig. 11. Profile of excess pore-water pressure with depth - test B $\left(Z^{*}=\right.$ depth below the base of the footing; $\left.D^{*}=2 \cdot 71 \mathrm{~m}\right)$ by the applied load, equal to $89 \mathrm{kPa}$ ), immediately after the load test and at two instances during the consolidation period.

According to the field data most of the excess pore-water pressure dissipation took place within the first $1000 \mathrm{~h}$ (about 42 days), and full dissipation occurred after about $10000 \mathrm{~h}$. The FEA predicts that the dissipation of most excess porewater pressure occurs between 4000 and $5000 \mathrm{~h}$, about four to five times longer than in the field. FEAs predict that undrained conditions prevail in the foundation soil for a longer period of time than that observed in the field.

Further evidence of this is the prediction of a time delay between the end of loading and the occurrence of the maximum excess pore-water pressure in piezometers PZ2 and PZ3 (and to a lesser degree PZ5). In EVP models, viscoplastic (creep) deformations are always predicted with the passing of time provided the stress state is located outside the yield surface. However, when a soil element located away from the drainage boundary attempts to creep, the prevalence of undrained conditions means that no volume change can occur and thus contractive excess pore pressures are predicted instead (i.e. stress relaxation occurs).

At the end of the monitoring period, when pore-water pressure dissipation is complete, discrepancies between the field data and the numerical predictions are likely to result from calibration errors of the piezometers, differences between the in-situ and adopted equilibrium groundwater regime and/or seasonal variations of the groundwater level (likely to affect only the shallower piezometers).

The results presented in Fig. 10 suggest that, in the top $5 \mathrm{~m}$, the field operational permeability was much higher than that assumed in the FEA. The value adopted for Bothkennar Clay is an upper bound for the values obtained from laboratory and in-situ tests, and an increase in relation to this value may be attributed to the occurrence of silty layers or other geological features not intercepted in the measurements mentioned above.

Horizontal movements. Two inclinometers, I1 and I2, were installed $0.15 \mathrm{~m}$ from the footing edge, on opposite sides of footing $\mathrm{B}$ (on the east and west facings). The data recorded during test $\mathrm{B}$ are shown in Fig. 12. Comparison of the data from the two inclinometers demonstrates the accentuated tilt of the footing that developed from the early loading stages, with horizontal movements being much smaller in inclinometer I1 than I2, at comparable times. Fig. 12 also includes the numerical predictions, which are taken at the vertical profile that passes through the edge of the footing. This was the most suitable location to obtain the numerical data; however, in reality, the inclinometers were located $0.15 \mathrm{~m}$ from the edge of the footing, and, consequently, although in the numerical predictions the horizontal movement is always zero at $z=0.8 \mathrm{~m}$ BGS (because of the displacement condition imposed at the base of the footing) that is not the case in the field data.

The numerical predictions provide a good match to the maximum horizontal displacement, overpredicting the measurements at I1 and underpredicting those at I2. In addition, the numerical predictions are able to recover satisfactorily the shape of the diagram of horizontal movements with

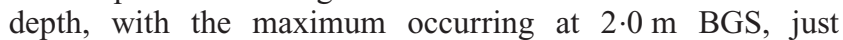
slightly above the depth given by the field measurements.

During test $\mathrm{C}$ inclinometers I1 and I2 were still active and readings were taken up to an applied load equal to $176 \mathrm{kPa}$, when the readings were stopped for safety reasons. Although not shown here, the measurements indicate that, despite the footing tilt, the horizontal displacement profiles given by the two inclinometers were very similar and their shape did not 

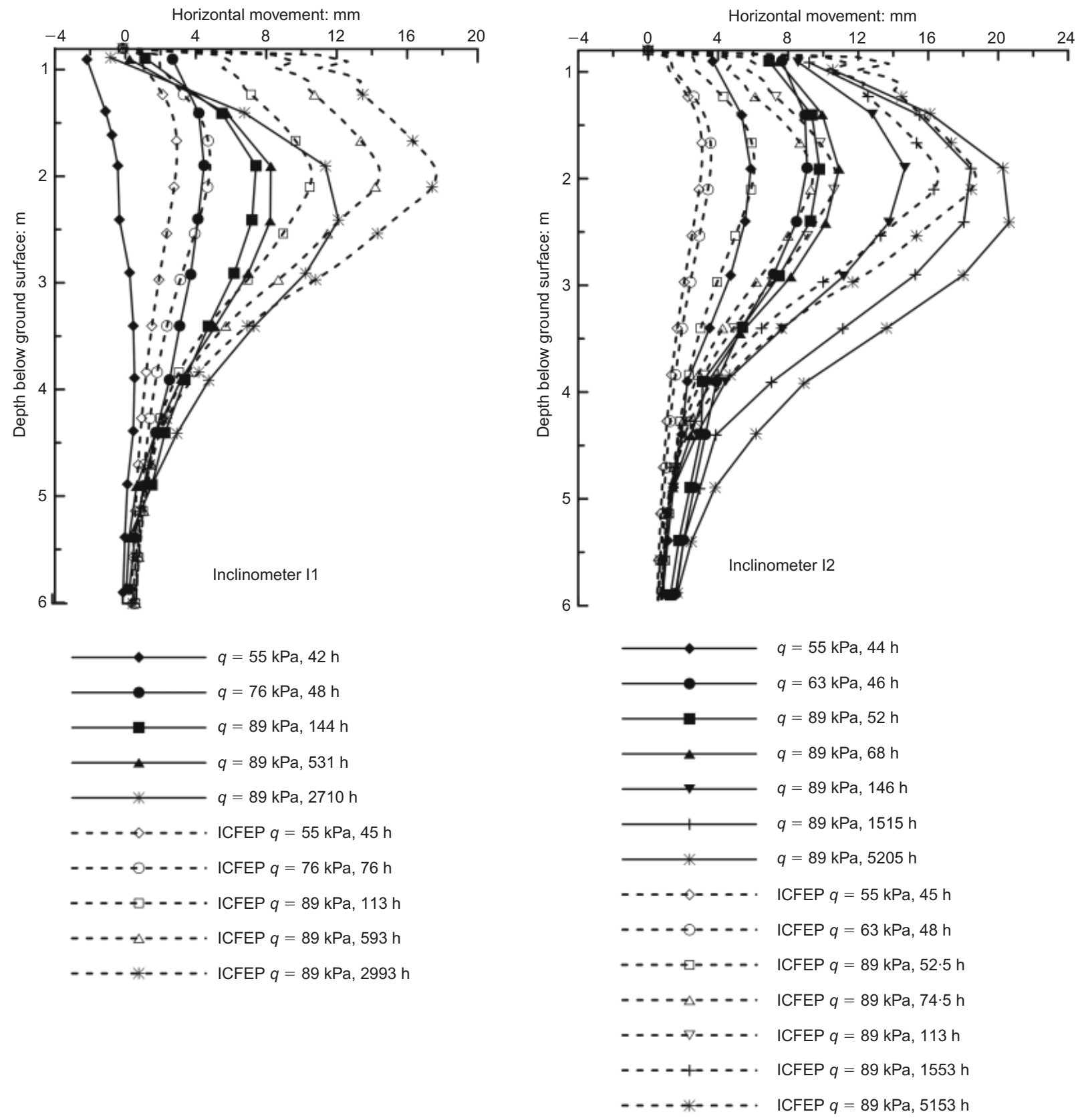

Fig. 12. Horizontal movements in the foundation during test $B$

change significantly with the level of applied load (see Lehane \& Jardine, 2003), being identical to that observed during test $\mathrm{B}$, with the maximum horizontal movement occurring about $2 \mathrm{~m}$ BGS. This behaviour is well recovered by the FEA.

\section{Investigation of the failure condition}

This section aims to characterise the ultimate conditions of the two footings and examine the ability of EVP models to provide failure loads. The average footing settlement at the end of the load tests was $180 \mathrm{~mm}$ and $230 \mathrm{~mm}$, for test $\mathrm{A}$ and $\mathrm{C}$, respectively, representing $7.3 \%$ and $8.5 \%$ of the corresponding equivalent diameter. These values may be identified with conditions at or close to failure. However, the FEAs of tests $\mathrm{A}$ and $\mathrm{C}$ showed no convergence problems throughout that could indicate the proximity to failure. To investigate the failure conditions of footing $\mathrm{A}$, a series of FEAs simulating the application of further load was per- formed, and the respective load-settlement curves are shown in Fig. 13.

Series ' $a$ ' corresponds to a coupled consolidation FEA during which the footing is loaded at $6 \mathrm{kPa} / \mathrm{h}$ after the last overnight break (a loading rate similar to that applied between hours 70 and 80, Fig. 6). The FEA fails to predict a well-defined failure load, and the footing is able to accommodate further loading even at very large displacements. To remove the effect of consolidation, series ' $b$ ' and ' $c$ ' consider that further loading of the footing occurs under undrained conditions at $6 \mathrm{kPa} / \mathrm{h}$ and $12 \mathrm{kPa} / \mathrm{h}$, respectively.

The load-displacement curve predicted by series ' $b$ ' is very similar to series ' $a$ ', with the former predicting a slightly higher load at the same footing settlement. This indicates that consolidation has a minimal effect on the predicted (continuous) increase in bearing capacity. Remarkably, when the loading rate is doubled from $6 \mathrm{kPa} / \mathrm{h}$ (series 'b') to $12 \mathrm{kPa} / \mathrm{h}$ (series 'c'), the resulting load-settlement curve moves upwards and the footing shows a stiffer response. 


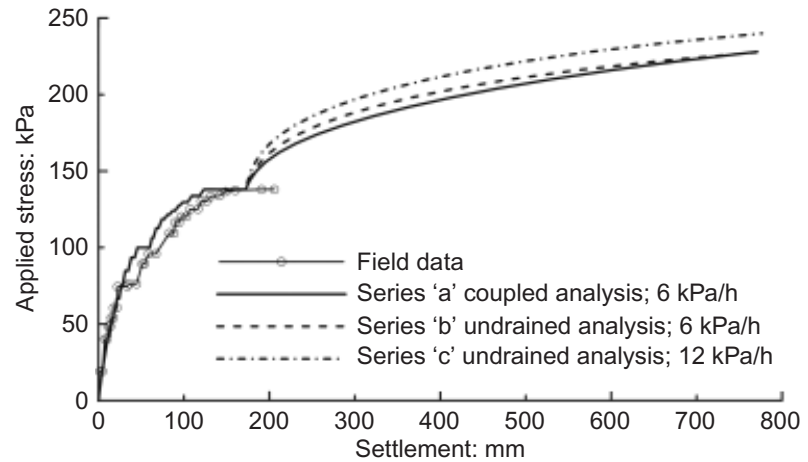

Fig. 13. Further loading of test A

The inability of the FEAs to predict a well-defined failure load results from the formulation of the model employed (e.g. Adachi et al., 1987). With the combination of model parameters and initial stress conditions adopted herein the model is not predicting (significant) strain softening (Fig. 3). Therefore, an increase in strain rate (as failure is approached) produces an increase in the soil's undrained shear strength, which inhibits the occurrence of failure. The application of a higher loading rate leads to the prediction of higher undrained shear strength values, and the footing is predicted to sustain more load at the same settlement value. If instead a post-peak brittle soil response was predicted by the model (either due to overconsolidation or the consideration of soil destructuration) it is very probable that a defined failure load would be predicted. That would be the case if the increase in the soil undrained shear strength due to the increase in strain rate (as failure is approached) were smaller than the strength loss due to softening. The model features that prevent a well-defined failure load to be reached in this study would still be operating, but would be masked by other features.

Figure 14 shows the numerical predictions obtained by means of coupled FEAs when further load is applied at $6 \mathrm{kPa} / \mathrm{h}$, after the last overnight break of tests $\mathrm{A}$ and $\mathrm{C}$, in terms of the incremental load-displacement curves. For the reasons given in the previous paragraph, the FEAs fail to predict a failure load for tests $\mathrm{A}$ and $\mathrm{C}$; however, it is noticeable that the initial response of footing $\mathrm{C}$, at identical values of additional load, is softer than that of footing $\mathrm{A}$, suggesting that the former footing is less stable.

Figure 15 presents the variation of settlement rate with time during tests $\mathrm{A}$ and $\mathrm{C}$ and compares the field data with the numerical predictions. For test $\mathrm{A}$ the field settlement rate was calculated from the mid-side target measurements shown in Fig. 6; for test $\mathrm{C}$ the field settlement rate data are those given by Lehane \& Jardine (2003). During the last load increments, the settlement rate recorded in test $\mathrm{C}$ is

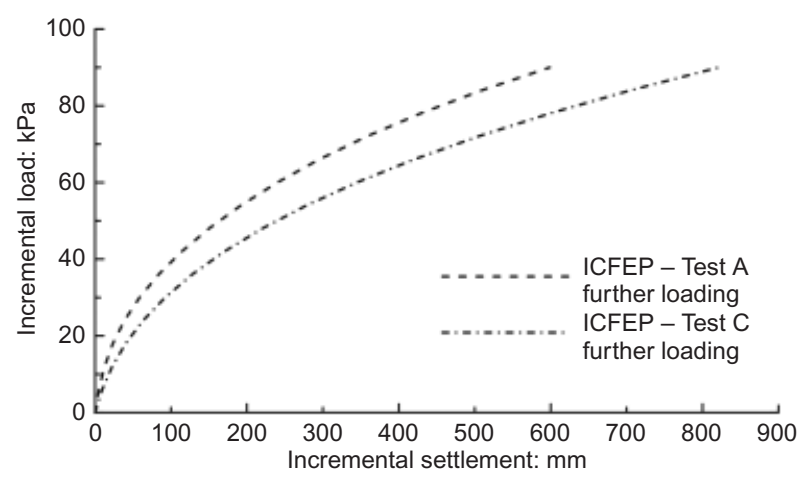

Fig. 14. Further loading of test $A$ and $C$ - comparison
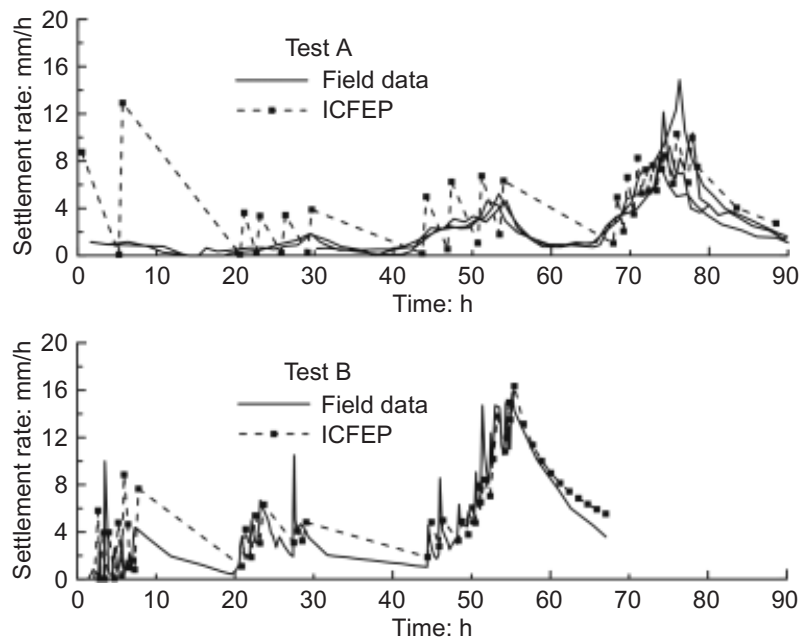

Fig. 15. Settlement rate during tests $A$ and $C$

systematically higher than the average of values found for test $\mathrm{A}$, and the reduction in settlement rate during the last overnight break is identical in the two tests. This suggests that footing A was marginally more stable, as indicated by the results in Fig. 14. The agreement between the analysis predictions and the field data is very good, particularly towards the end of loading. During the early loading stages, and in particular for test A, the numerical predictions show large oscillations on the predicted settlement rate because of the reduced number of analysis increments.

\section{Failure mechanism}

There are no field measurements of horizontal displacements in the foundation during test A. The horizontal displacement data obtained during test B (Fig. 12) suggest that up to $q / q_{\mathrm{f}}=0.67$ the shape of the profile of horizontal displacements was insensitive to the applied load. Noting the similarities between tests $\mathrm{A}$ and $\mathrm{B}$, it is reasonable to assume that the profile of horizontal displacements shown in Fig. 12 is representative of that of test $\mathrm{A}$ at the end of loading. In that case, the failure mechanism of test $\mathrm{A}$ was quite shallow, with the failure surface passing just below $2 \mathrm{~m}$ BGS (at that location). Accordingly, the initial peak $S_{\mathrm{u}}$ profile (Fig. 5), valid for test $\mathrm{A}$, presents its minimum at about $3.0 \mathrm{~m}$ depth, with a small gradient between $2 \mathrm{~m}$ and $3 \mathrm{~m}$ BGS. Fig. 16 shows the incremental displacement vectors in the foundation predicted by the FEAs at the end of test A and at very large settlements when further loading is simulated. The FEAs reproduce a concentration of plastic deformation immediately below the footing, denoting an insipient and shallow punch-through type failure, but fail to predict a well-defined, localised failure mechanism (and thus a defined failure load), even after subsequent loading.

Figure 16 also shows the incremental displacement vectors in the foundation soil predicted by the FEAs at the end of test $\mathrm{C}$ and after subsequent loading, at very large settlements. The application of preload for a period of 11 years does not produce a visible change in the predicted failure mechanism. During test $\mathrm{C}$ the inclinometers were monitored up to $q=176 \mathrm{kPa}$ and the data suggest that the shape of the profile of horizontal displacements is identical to that identified during test $\mathrm{B}$, but these measurements may not be representative of the behaviour at failure (Lehane \& Jardine, 2003).

Figure 5 shows the profile of peak undrained shear strength available at the footing axis just before test $\mathrm{C}$, as predicted by the EVP model under triaxial compression at 


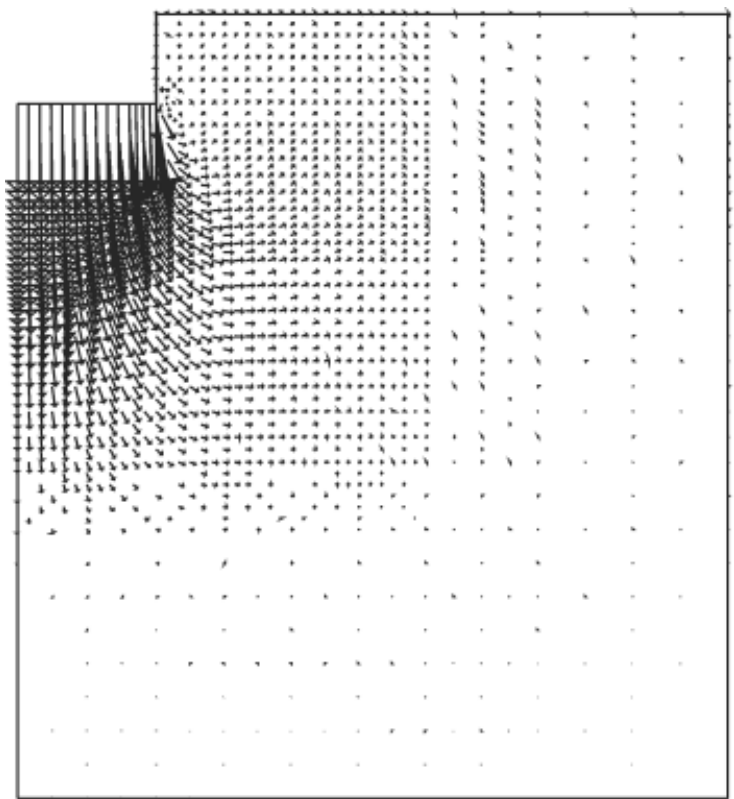

(a)

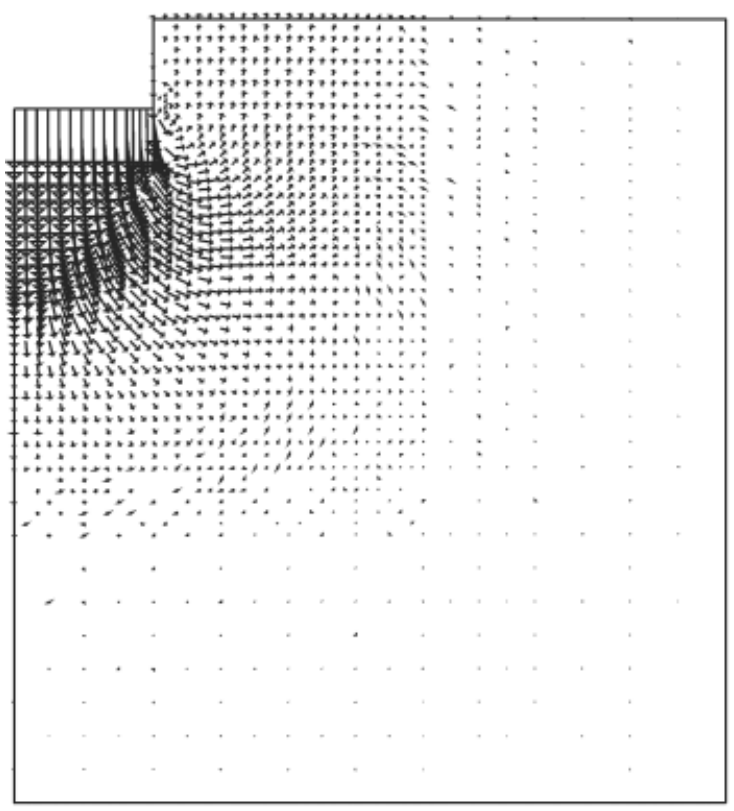

(c)

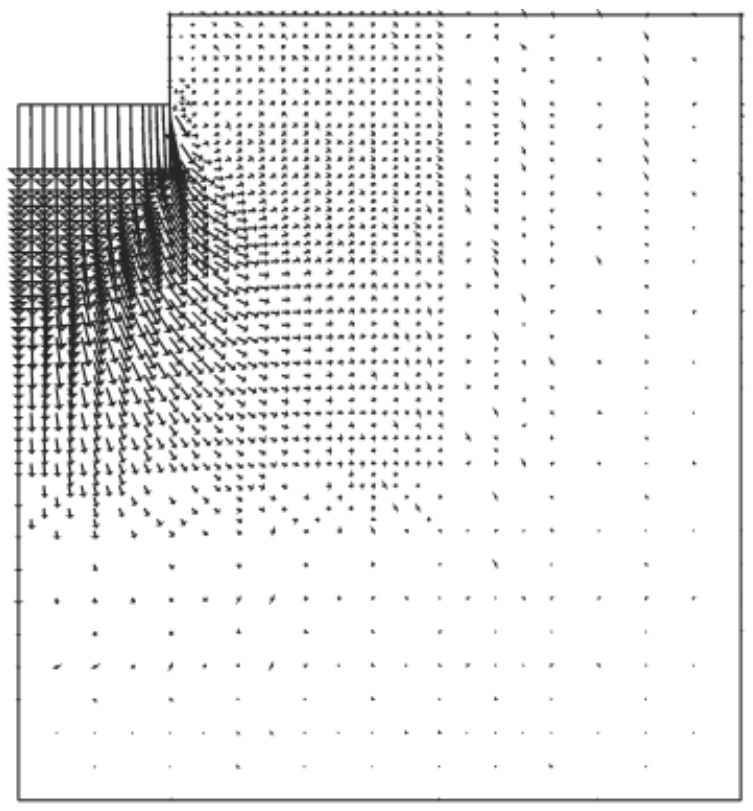

(b)

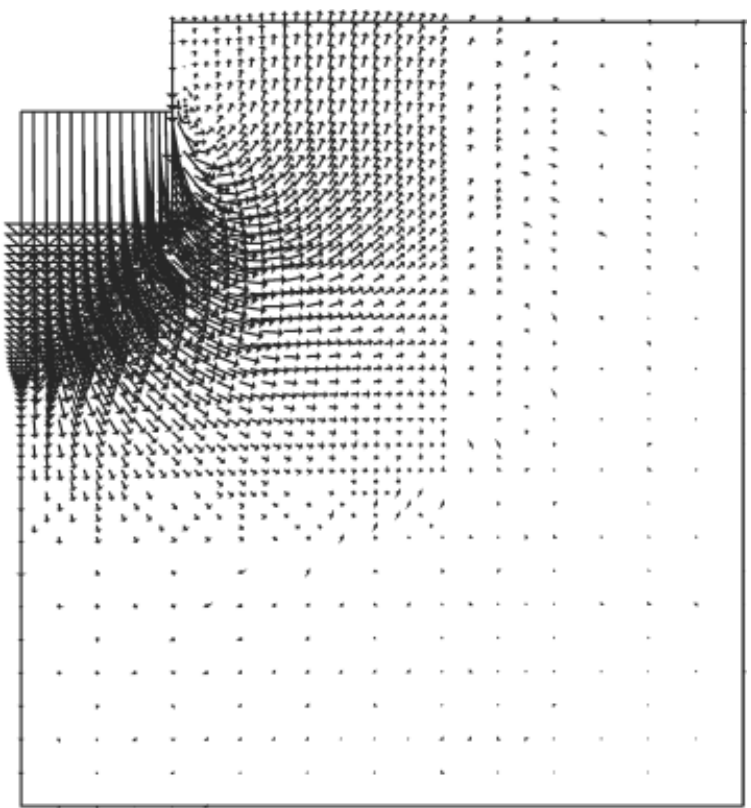

(d)

Fig. 16. Incremental displacements at the end of tests $A$ and $C$ (vectors not at the same scale in the four situations): (a) test $A$, before footing unloading; (b) test $\mathrm{C}$, before footing unloading; (c) test $\mathrm{A}$, after further load; (d) test $\mathrm{C}$, after further load

$4.5 \% /$ day axial strain. The predicted increase in foundation undrained shear strength is due to the increase in mean effective stress and the development of creep strains. Therefore, the largest increments are likely to occur where the application of preload results in larger stress increments. The FEAs predict a significant increase in the available undrained shear strength to about $4.5 \mathrm{~m}$ BGS, where the minimum now occurs. For the numerical analyses, the gradient in undrained strength between $2 \mathrm{~m}$ and $4 \mathrm{~m}$ BGL was not sufficient to move the failure mechanism downwards, but it is not clear if that was the case in the field.

Discrepancies between the profile of undrained shear strength available in the field just before test $\mathrm{C}$ and that shown in Fig. 5 may result from the following.

(a) Differences in the distribution of total stress increments imposed to the foundation soil during the application of preload (i.e. test B); Fig. 11 shows that the bulb of excess pore-water pressure predicted by the FEAs is shallower than that given by the field data. Largest gains in undrained strength are expected where larger stress increments have occurred.

(b) In the FEAs the same model parameters were adopted for the full depth of the soil deposit; however, that is unlikely to be the case, with the unweathered Bothkennar Clay (unit IV) being more compressible and more prone to creep delayed deformations (and thus soil hardening) than the superficial materials.

(c) The EVP model is unable to reproduce the post-peak strength loss associated with the soil destructuration during shearing (at the time of the application of the preload). While the effect will be minimal in the materials that constitute the recent tidal deposits and the superficial weathered Bothkennar Clay, it is expected 
to be important in the competent unweathered soft Bothkennar Clay. As a consequence, the undrained shear strength predicted by the FEA could be higher than that actually available in the foundation at the start of test C.

(d) Application of the bearing capacity expression by Hansen (1970), $q_{\mathrm{r}}=(2+\pi) S_{\mathrm{u}}\left(1+s_{\mathrm{c}}+d_{\mathrm{c}}\right)$, that ignores the effect of the footing tilt, where $S_{\mathrm{u}}$ is the soil's undrained shear strength (assumed constant), $d_{\mathrm{c}}$ is the depth factor, $d_{\mathrm{c}}=0.4 \mathrm{D} / \mathrm{B}$, and $s_{\mathrm{c}}$ is the shape factor, $s_{\mathrm{c}}=0 \cdot 2 \mathrm{~B} / \mathrm{L}$ (with $D=$ depth of the footing and $B$ and $L$ are the smaller and the larger dimension of the footing in plan, respectively), gives an operational $S_{\mathrm{u}}$ during test A equal to $20.0 \mathrm{kPa}$, identical to the average $S_{\mathrm{u}}$ over a depth $B$ below the base of the footing shown in Fig. 5. This suggests that during test A strain softening was not significant.

(e) On the other hand, the model does not simulate the development of soil structure during the consolidation period that could, at least partially, cancel the above effect.

$(f)$ In addition, the EVP model does not incorporate induced anisotropy, that is, the rotation of the state boundary surface in relation to the current stress state, which would lead to a further increase in the foundation's undrained strength due to the preload, which has imposed considerable levels of strength mobilisation within the foundation.

Bearing in mind the above issues and noting the remarkable good agreement between field data and numerical predictions in terms of the overall load-displacementdisplacement rate behaviour of test $\mathrm{C}$, it is thought that the field undrained shear strength profile in the foundation before test $\mathrm{C}$ is not that dissimilar from the one shown in Fig. 5.

\section{CONCLUDING REMARKS}

This paper presents a numerical study on performance of two instrumented surface footings at the Bothkennar research site, in which the foundation soil was modelled using an EVP model that simulates permanent strain rate effects on the soil response, that is, isotach viscosity. The adopted ground profile and model parameters are defined based on extensive field and laboratory testing data available in the literature.

The developed numerical model was based on the following assumpitons: $(a)$ the same model parameters were adopted over the full depth of the soil profile, given that there were no specific characterisation data within the superficial materials, and differences in strength and stiffness were attributed to differences in the initial soil state (OCR and $\left.K_{0}\right)$; (b) the analyses do not account for the loss of soil structure during plastic deformation, the development of structure with time, or $(c)$ the occurrence of induced anisotropy during loading. The two latter points contrast with the fact that Bothkennar Clay was found to be a structured, anisotropic and sensitive material. Despite the above, the numerical analyses show very good agreement with the field measurements, in particular in terms of the overall loaddisplacement-displacement rate relationship of the three load tests. This suggests that destructuration and evolving anisotropy may have played a comparatively minor role in the observed field response compared to strain rate effects.

The work presented here emphasises the fact that time and rate effects need to be accounted for when examining the long-term behaviour of geostructures, when the applied loading rates are atypical for that type of structure, or when the consideration of soil hardening associated with timedelayed viscous deformation is important (e.g. staged con- struction). The EVP model used herein has been shown to reproduce such situations adequately. Furthermore, a flexible creep law that allows the consideration of soil creep nonlinearity needs to be considered in order to obtain good predictions of the long-term deformations of geostructures.

\section{ACKNOWLEDGEMENT}

The authors would like to thank Fundação Ciência e Tecnologia, Portugal for sponsoring the doctoral programme of T. M. Bodas Freitas at Imperial College, London, during which this work was developed.

\section{NOTATION}

$B$ smaller dimension of footing in plan

$c^{\prime}$ cohesion

$D$ depth of footing

$D^{*}$ equivalent footing diamter

$\left[D^{\prime}\right]$ elastic constitutive matrix

$d_{\mathrm{c}}$ depth factor

$G$ shear modulus

$g$ plastic potential

$J$ deviatoric stress invariant

$K$ bulk modulus

$K_{0}$ coefficient of earth pressures at rest

$L$ larger dimension of the footing in plan

$L_{\mathrm{f}}$ load factor

$M$ inclination of the critical state line in $p^{\prime}-q$ space under triaxial compression

$p^{\prime}$ mean effective stress

$p_{\mathrm{i}}^{\prime} \quad$ initial mean effective stress

$p_{\mathrm{m}}^{\prime}$ mean effective stress at $J=0$ on the current loading surface

$p_{\mathrm{mc}}^{\prime} \quad$ size of loading surface corresponding to largest normally consolidated stress state that the soil element has experienced

$q$ triaxial deviatoric stress

$q_{\mathrm{r}}$ bearing capacity

$S_{\mathrm{u}} \quad$ undrained shear strength

$s_{\mathrm{c}}$ shape factor

$t_{0}$ real time associated with the reference time line

$V$ specific volume

$z$ depth below ground surface

$\alpha$ model parameter that controls the shape of the loading surface

$\Delta t$ time increment

$\left\{\Delta \varepsilon^{\mathrm{el}}\right\} \quad$ elastic strain increment

$\left\{\Delta \varepsilon^{\mathrm{T}}\right\} \quad$ total strain increment

$\left\{\Delta \varepsilon^{\mathrm{vp}}\right\} \quad$ viscoplastic strain increment

$\left\{\Delta \sigma^{\prime}\right\} \quad$ effective stress increment

$\varepsilon_{\mathrm{vol}}$ current volumetric strain

$\varepsilon_{\text {vol, m }}$ current volumetric strain at $p^{\prime}=p_{\mathrm{m}}^{\prime}$

$\varepsilon_{\mathrm{vol}, \mathrm{m}}^{\mathrm{ref}}$ volumetric strain on the reference line at $p^{\prime}=p_{\mathrm{m}}^{\prime}$

$\varepsilon_{\mathrm{vol}, \mathrm{m}, \text { Limit }}^{\mathrm{vp}}$ limit to the amount of viscoplastic volumetric strain

$\kappa / V$ model parameter

$\lambda / V$ model parameter

$\mu$ model parameter that controls shape of loading surface

$v$ Poisson ratio

$\sigma_{\mathrm{v} 0}^{\prime}$ in-situ vertical effective stress

$\Phi$ viscoplastic scalar multiplier

$\phi^{\prime}$ angle of shearing resistance

$\phi_{\text {cs }}^{\prime} \quad$ angle of shearing resistance at critical state

$\psi_{0} / V$ model parameter

\section{REFERENCES}

Aboshi, H. (2004). Long-term effect of secondary consolidation on consolidation settlement of marine clays. Advances in geotechnical engineering: The Skempton conference. London, UK: Thomas Telford.

Adachi, T., Oka, F. \& Mimura, M. (1987). Mathematical structure of an overstress elasto-viscoplastic model for clay. Soils Found. 27, No. 3, 31-42. 
Augustesen, A., Liingaard, M. \& Lade, PV. (2004). Evaluation of the time-dependent behaviour of soils. Int. J. Geomech. 4, No. 3, 137-156.

Bjerrum, L. (1967). Engineering geology of Norwegian normallyconsolidated marine clays as related to the settlements of buildings. Géotechnique 17, No. 2, 81-118, http://dx.doi.org/10.1680/ geot.1967.17.2.83.

Bodas Freitas, T. M., Potts, D. M. \& Zdravkovic, L. (2011). A time dependent constitutive model for soils with isotach viscosity. Comput. Geotech. 38, No. 6, 809-820.

Bodas Freitas, T. M., Potts, D. M. \& Zdravkovic, L. (2012a). Implication of the definition of the $\Phi$ function in elastic viscoplastic model. Géotechnique 62, No. 7, 643-648, http:// dx.doi.org/10.1680/geot.10.P.053.

Bodas Freitas, T. M., Potts, D. M. \& Zdravkovic, L. (2012b). The effect of creep on the short-term bearing capcity of pre-loaded footings. Comput. Geotech. 42, 99-108.

Gildea, P. A. (1990). An investigation into the yielding of soft clay. MSc dissertation, Imperial College, University of London, London, UK.

Grimstad, G., Degago, S. A., Nordal, S. \& Karstunen, M. (2010) Modeling creep and rate effects in structured anisotropic soft clays. Acta Geotech. 5, No. 1, 69-81.

Hansen, B. (1970). A revised and extended formula for bearing capacity, Bulletin no. 28, pp. 5-11. Lyngby, Denmark: Danish Geotechnical Institute.

Hight, D. W., Bond, A. J. \& Legge, J. D. (1992). Characterization of the Bothkennar Clay: an overview. Géotechnique 42, No. 2, 303-347, http://dx.doi.org/10.1680/geot.1992.42.2.303.

Hinchberger, S. D. \& Qu, G. (2009). Viscoplastic constitutive approach for rate sensitive structured clays. Can. Geotech. J. 46, No. 6, 609-626.

Jardine, R. J., Potts, D. M., Fourie, A. B. \& Burland, J. B. (1986). Studies of the influence of non-linear stress-strain characteristics in soil-structure interaction. Géotechnique 36, No. 3, 377-396, http://dx.doi.org/10.1680/geot.1986.36.3.377.

Jardine, R. J., Lehane, B. M., Smith, P. R. \& Gildea, P. A. (1995). Vertical loading experiments on rigid pad foundations at Bothkennar. Géotechnique 45, No. 4, 573-597, http://dx.doi.org/ 10.1680/geot.1995.45.4.573

Karstunen, M. \& Yin, Z.-Y. (2010). Modelling time dependent behaviour of Murro test embankment. Géotechnique 60, No. 10, 735-749, http://dx.doi.org/10.1680/geot.8.P.027.

Karstunen, M., Yin, Z. Y., Koskinen, M., Leoni, M. \& Vermeer, PA. (2008). Some recent developments in constitutive modelling of soft clays. Proceedings of the 12th IACMAG, Goa, India, pp. 966-975. New York, NY, USA: Curran Associates.

Kutter, B. L. \& Sathialingam, N. (1992). Elasto-viscoplastic modelling of the rate dependent behaviour of clays. Géotechnique $\mathbf{4 2}$, No. 3, 427-441, http://dx.doi.org/10.1680/geot.1992.42.3.427.

Lagioia, R., Puzrin, A. M. \& Potts, D. M. (1996). A new versatile expression for yield and plastic potential surfaces. Comput. Geotech. 19, No. 3, 171-191.

Lambe, T. W. (1973). Predictions in soil engineering. Géotechnique 23, No. 2, 151-201, http://dx.doi.org/10.1680/geot.1973.23.2. 151.

Lehane, B. M. \& Jardine, R. J. (2003). Effects of long-term preloading on the performance of a footing on clay. Géotechnique 53, No. 8, 689-695, http://dx.doi.org/10.1680/geot.2003.53.8. 689.

Leroueil, S., Kabbaj, M., Tavenas, F. \& Bouchard, R. (1985). Stress-strain-time rate relation for the compressibility of sensi- tive natural clays. Géotechnique 35, No. 2, 159-180, http:// dx.doi.org/10.1680/geot.1985.35.2.159.

Leroueil, S., Lerat, P., Hight, D. W. \& Powell, J. J. M. (1992) Hydraulic conductivity of a recent estuarine silty clay at Bothkennar. Géotechnique 42, No. 2, 275-288, http://dx.doi.org/ 10.1680/geot.1992.42.2.275.

Liingaard, M., Augustesen, A. \& Lade, P. V. (2004). Characterization of models for the time-dependent behaviour of soils. Int. J. Geomech. 4, No. 3, 157-177.

Losacco, N. (2007). Raising of embankments on soft clay. MSc thesis, Department of Civil and Environmental Eng., Imperial College, London, UK.

Nash, D. F. T., Powell, J. J. M. \& Lloyd, I. M. (1992a). Initial investigations of the soft clay test site at Bothkennar. Géotechnique 42, No. 2, 163-181, http://dx.doi.org/10.1680/geot.1992.42.2.163.

Nash, D. F. T., Sills, G. C. \& Davison, L. R. (1992b). Onedimensional consolidation testing of soft clay from Bothkennar. Géotechnique 42, No. 2, 241-256, http://dx.doi.org/10.1680/ geot.1992.42.2.241.

Perzyna, P. (1963). The constitutive equations for work-hardening and rate sensitive plastic materials. Proceedings of vibration problems, Warsaw, vol. 4, pp. 281-290.

Potts, D. M. \& Zdravkovic, L. (1999). Finite element analysis in geotechnical engineering: theory. London, UK: Thomas Telford.

Potts, D. M. \& Zdravkovic, L. (2001). Finite element analysis in geotechnical engineering: application. London, UK: Thomas Telford.

Randolph, M. F., Jamiolkowski, M. B. \& Zdravkovic, L. (2004). Load carrying capacity of foundations. Advances in geotechnical engineering. Proceedings of the Skempton memorial conference, vol. 1, pp. 227-240. London, UK: Thomas Telford.

Roscoe, K. H. \& Burland, J. B. (1968). On the generalised stressstrain behaviour of 'wet' clay. In Engineering plasticity (eds J. Heyman and F. A. Leckie), pp. 535-609. Cambridge, UK: Cambridge University Press

Rowe, R. K. \& Hinchberger, S. D. (1998). The significance of rate effects in modelling the Sackville test embankment. Can. Geotech. J. 35, No. 3, 500-516.

Smith, P. R. (1992). The behaviour of natural high compressibility clay with special reference to construction on soft ground. $\mathrm{PhD}$ thesis, Imperial College, University of London, UK

Smith, P. R., Jardine, R. J. \& Hight, D. W. (1992). The yielding of Bothkennar Clay. Géotechnique 42, No. 2, 257-274, http:// dx.doi.org/10.1680/geot.1992.42.2.257.

Yin, J.-H. (1999). Non-linear creep of soils in oedometer tests. Géotechnique 49, No. 5, 699-707, http://dx.doi.org/10.1680/ geot.1999.49.5.699.

Yin, J.-H. \& Graham, J. (1989). Viscous-elasto-plastic modelling of one-dimensional time-dependent behaviour of clays. Can. Geotech. J. 26, No. 2, 199-209.

Yin, Z. Y. \& Karstunen, M. (2008). Influence of anisotropy, destructuration and viscosity on the behavior of an embankment on soft clay. Proceedings of the 12th IACMAG, Goa, India, pp. 4728-4735. New York, NY, USA: Curran Associates.

Yin, J.-H., Zhu, J.-G. \& Graham, J. (2002). A new elastic viscoplastic model for time-dependent behaviour of normally and overconsolidated clays: theory and verification. Can. Geotech. J. 39, No. 1, 157-173

Zdravkovic, L., Potts, D. M. \& Jackson, C. (2003). Numerical study of the effect of pre-loading on undrained bearing capacity. ASCE Int. J. Geomech. 3, No. 1/2, 1-10. 